\title{
Cell cycle checkpoint signaling through the ATM and ATR kinases
}

\author{
Robert T. Abraham ${ }^{1}$ \\ Department of Pharmacology and Cancer Biology, Duke University Medical Center, Durham, North Carolina 27710, USA
}

The genomes of eukaryotic cells are under continuous assault by environmental agents (e.g., UV light and reactive chemicals) as well as the byproducts of normal intracellular metabolism (e.g., reactive oxygen intermediates and inaccurately replicated DNA). Whatever the origin, genetic damage threatens cell survival, and, in metazoans, leads to organ failure, immunodeficiency, cancer, and other pathologic sequelae. To ensure that cells pass accurate copies of their genomes on to the next generation, evolution has overlaid the core cell-cycle machinery with a series of surveillance pathways termed cell-cycle checkpoints. The overall function of these checkpoints is to detect damaged or abnormally structured DNA, and to coordinate cell-cycle progression with DNA repair. Typically, cell-cycle checkpoint activation slows or arrests cell-cycle progression, thereby allowing time for appropriate repair mechanisms to correct genetic lesions before they are passed on to the next generation of daughter cells. In certain cell types, such as thymocytes, checkpoint proteins link DNA strand breaks to apoptotic cell death via induction of p53. Hence, loss of either of two biochemically connected checkpoint kinases, ATM or Chk2, paradoxically increases the resistance of immature $\left(\mathrm{CD}^{+} \mathrm{CD} 8^{+}\right) \mathrm{T}$ cells to ionizing radiation (IR)-induced apoptosis (Xu and Baltimore 1996; Hirao et al. 2000).

In a broader context, cell-cycle checkpoints can be envisioned as signal transduction pathways that link the pace of key cell-cycle phase transitions to the timely and accurate completion of prior, contingent events. It is important to recognize that checkpoint surveillance functions are not confined solely to the happenings within the nucleus-extranuclear parameters, such as growth factor availability and cell mass accumulation, also govern the pace of the cell cycle (Stocker and Hafen 2000). However, for the purposes of this review we will focus exclusively on the subset of checkpoints that monitor the status and structure of chromosomal DNA during cell-cycle progression (Fig. 1). These checkpoints contain, as their most proximal signaling elements, sensor proteins that scan chromatin for partially replicated

\footnotetext{
${ }^{1}$ Present address: The Burnham Institute, 10901 N. Torrey Pines Road, La Jolla, CA 92037, USA

E-MAIL abraham@burnham.org; FAX (858) 713-6268.

Article and publication are at http://www.genesdev.org/cgi/doi/10.1101/ gad.914401.
}

DNA, DNA strand breaks, or other abnormalities, and translate these DNA-derived stimuli into biochemical signals that modulate the functions of specific downstream target proteins.

Despite the recent explosion of information regarding the molecular components of cell-cycle checkpoints in eukaryotic cells, we still have only a skeletal understanding of both the identities of the DNA damage sensors and the mechanisms through which they initiate and terminate the activation of checkpoints. However, members of the Rad group of checkpoint proteins, which include Rad17, Rad1, Rad9, Rad26, and Hus1 (nomenclature based on the Schizosaccharomyces pombe gene products) are widely expressed in all eukaryotic cells, and are prime suspects in the lineup of candidate DNA damage sensors (Green et al. 2000; O'Connell et al. 2000). Three of these Rad proteins, Rad1, Rad9, and Hus1, exhibit structural similarity to the proliferating cell nuclear antigen (PCNA), and accumulating evidence supports the idea that this similarity may extend to function as well (Thelen et al. 1999; Burtelow et al. 2000). During DNA replication, PCNA forms a homotrimeric complex that encircles DNA, creating a "sliding clamp" that tethers DNA polymerase $\delta$ to the DNA strand. Rad1, Rad9, and Hus1 are also found as a heterotrimeric complex in intact cells, and it has been postulated that the Rad1-Rad9-Hus1 complex encircles DNA at or near sites of damage to form a checkpoint sliding clamp (CSC) (O'Connell et al. 2000), which could serve as a nucleus for the recruitment of the checkpoint signaling machinery to broken or abnormally structured DNA. The analogy between PCNA and the Rad1-Rad9-Hus1 complex extends even further. The loading of the PCNA clamp onto DNA is controlled by the clamp loading complex, replication factor C (RFC). Interestingly, yet another member of the Rad family, Rad17, bears homology to the RFC subunits and, in fact, associates with RFC subunits to form a putative checkpoint clamp loading complex (CLC) that governs the interaction of the Rad1Rad9-Hus1 CSC with damaged DNA (Green et al. 2000; $\mathrm{O}^{\prime}$ Connell et al. 2000). Although this model is fascinating, rigorous biochemical evaluations of the interplay between the CLC and CSC complexes, and the interactions of both complexes with damaged chromatin, are needed before the model can be accepted without reservation. 


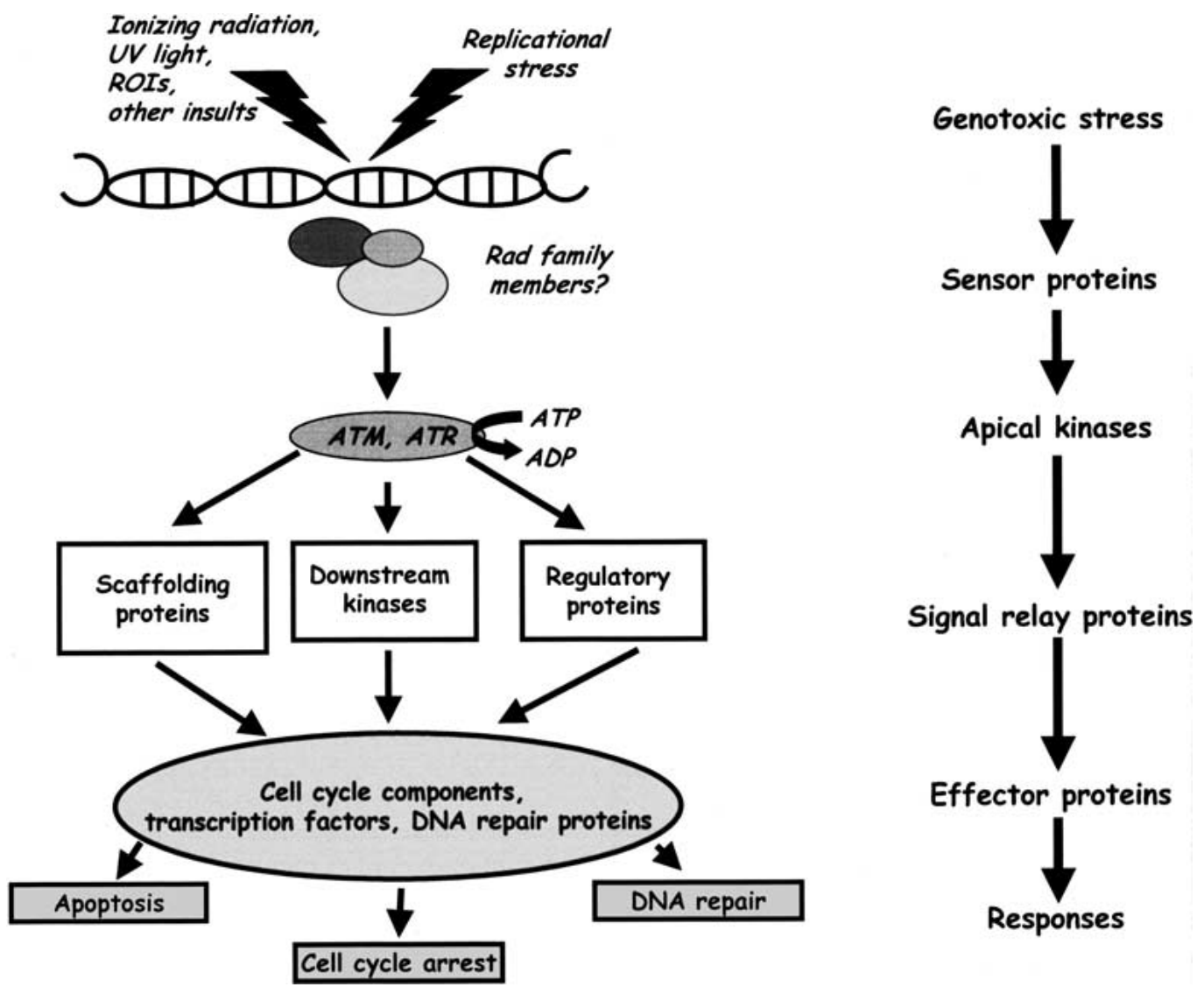

Figure 1. A generic cell-cycle checkpoint signaling pathway. (ROI) Reactive oxygen intermediate.

Moving downstream of the sensor apparatus, we find additional analogies between checkpoint pathways and standard signal transduction cascades, in that both rely heavily on protein phosphorylation for signal transmission and amplification. Cell-cycle checkpoint kinases belong largely, if not entirely, to the serine-threonine kinase family, and the proteins they target for modification range from more downstream members of the checkpoint pathway itself (e.g., additional protein kinases or noncatalytic scaffolding proteins) to distal elements that mediate cell-cycle arrest and DNA repair responses (e.g., the Cdc25C phosphatase or type 2A histones) (Rogakou et al. 1999; Downs et al. 2000; O'Connell et al. 2000; Paull et al. 2000).

During the very earliest stages of checkpoint activation, DNA damage sensors relay information, via a stillelusive mechanism, to members of a recently defined family of phosphoinositide 3-kinase related kinases (PIKKs; Tibbetts and Abraham 2000). In mammalian cells, two PIKK family members, ATM (âtaxia-telangi-

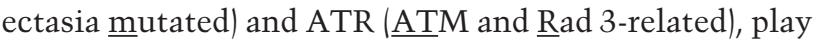
critical roles in early signal transmission through cellcycle checkpoints. Homologs of ATM and ATR are present in all eukaryotic cell types examined to date, including budding and fission yeast. The present review focuses on the biochemistry and function of the mammalian checkpoint kinases, ATM and ATR, with only brief references to the precedent literature from yeast model systems. For more information regarding the yeast ATM/ATR homologs, or a more global overview of cell-cycle checkpoints, the reader is referred to several recent reviews (Elledge 1996; Weinert 1997; Lowndes and Murguia 2000; Tibbetts and Abraham 2000; Zhou and Elledge 2000).

\section{The PIKK family}

As mentioned earlier, ATM and ATR belong to a structurally unique family of protein serine-threonine kinases whose catalytic domains share a clear evolutionary relationship with those of mammalian and yeast phosphoinositide 3-kinases (Hunter 1995; Zakian 1995; Tibbetts and Abraham 2000). The molecular cloning of PIKK-encoding cDNAs began with the isolation of the products of the target of rapamycin genes (TOR1 and TOR2) from Saccharomyces cerevisiae (Cafferkey et al. 1994; Helliwell et al. 1994), followed by the cloning of the mammalian ortholog, termed mTOR (also called FRAP or RAFT1) (Brown et al. 1994; Sabatini et al. 1994; Sabers et al. 1995). As the TOR acronym indicates, these PIKK family members are the protein targets of the potent antifungal and immunosuppressive agent, rapamycin (for reviews, see Abraham and Wiederrecht 1996; Gingras et al. 2001). Shortly thereafter, a flurry of reports 
described a series of yeast, fly, worm, and mammalian proteins that also expressed the characteristic phosphoinositide 3-kinase-like catalytic domain (Zakian 1995; Tibbetts and Abraham 2000). One of the cloned cDNAs, termed $A T M$, attracted widespread attention, because mutations in this gene underlie the heritable chromosomal instability disorder, ataxia-telangiectasia (A-T) (Savitsky et al. 1995). On the heels of these initial papers, the ATR cDNA was uncovered during a search of an EST database for additional gene products bearing the mTOR/FRAP-like catalytic domain (Cimprich et al. 1996).

Recent studies in the worm, Caenorhabditis elegans, and in human cells have identified yet another large $(\sim 390 \mathrm{kD})$ protein kinase whose catalytic domain indicates membership in the PIKK family. The C. elegans gene, $S M G-1$, encodes a putative protein kinase that plays an essential role in the elimination of RNA species containing premature termination codons, a process termed nonsense-mediated mRNA decay (NMD; Maquat 2000). Subsequently, a human PIKK family member bearing regional sequence homology to SMG-1 was cloned independently by at least two research teams (Denning et al. 2001; K.M. Brumbaugh, D.M. Otterness, and R.T. Abraham, in prep.). Although the human cDNA has been designated hSMG-1 by one group (Denning et al. 2001), we suggest that this name remain provisional until a role for this PIKK family member in NMD is unequivocally shown. Our own results indicate that hSMG1 is found in both the nucleus and cytoplasm, and, like ATM and ATR, exhibits phosphotransferase activity toward a variety of proteins containing Ser-Gln motifs under in vitro assay conditions. At this early stage, it seems quite likely that the putative hSmg1 homolog will join ATM and ATR as a stress-responsive protein kinase, and that, in addition to its predicted role in NMD, this intriguing addition to the PIKK family will offer further insights into stress-induced signaling in mammalian cells.

In addition to the sequence homology in the catalytic domains, the PIKK family members exhibit a similar overall structural organization (see Fig. 2 for examples). When compared with other kinases (protein or lipid), the PIKKs stand out immediately as very large polypeptides, with molecular masses ranging from $\sim 300 \mathrm{kD}$ to $>500$ $\mathrm{kD}$. The catalytic domains $(\sim 300$ amino acids) of the
PIKK family members are located near their carboxyl termini, and are flanked by two loosely conserved domains termed FAT (FRAP/ATM/TRRAP) and FATC (the "C" indicates carboxy-terminal) (Bosotti et al. 2000). Although the FAT/FATC domains contain no identifiable catalytic sequences, the fact that these domains are always expressed in pairs has raised the still untested hypothesis that they interact in an intramolecular fashion, and thereby regulate the conformation of the interposed kinase domain (Bosotti et al. 2000). Despite the sequence similarity to phosphoinositide kinases, the catalytic domains of the PIKKs appear to transfer phosphate exclusively to protein rather than lipid substrates.

The current members of the PIKK family can be grouped into six subfamilies on the basis of both sequence homology and function (Durocher and Jackson 2001) (Table 1). The mammalian members of five of the six subfamilies are known to phosphorylate protein substrates on serine or threonine residues. In mammalian cells, ATM and ATR are thought to share responsibilities as the apical protein kinases in all of known cellcycle checkpoints, with the possible exception of the mitotic spindle checkpoint, which is activated by treatment with nocodazole, an inhibitor of microtubule polymerization. The catalytic subunit of DNA-dependent protein kinase (DNA-PK $\mathrm{Cs}_{\mathrm{cs}}$ ) functions as a heterotrimeric complex containing two Ku subunits (Ku-70 and $\mathrm{Ku}-80)$, and makes its own crucial contribution to genome maintenance by overseeing the nonhomologous end-joining (NHEJ) pathway of DNA double-strand break (dsb) repair (Smith and Jackson 1999). On the other hand, mTOR plays no identifiable role in genome surveillance; rather, this PIKK coordinates $G_{1}$ phase progression with the supply of nutrients and growth factors (Gingras et al. 2001). As discussed previously, a very recent addition to this list is hSMG-1, which has no yeast counterparts, but, based on sequence homology to the Caenorhabditis elegans SMG-1 protein, is predicted to function in NMD (Denning 2001). Our group has cloned a partially overlapping open reading frame, and we have provisionally termed the encoded polypeptide ATX (K.M. Brumbaugh, D.M. Otterness, and R.T. Abraham, in prep.). Finally, the members of the TRAPP subfamily express catalytic domains that have sustained disabling mutations during eukaryotic evolution (Grant et al. 1998). The latter pro-
ATM

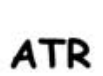

FAT PI3Kc C 3,056 aa
Figure 2. Schematic diagrams of ATM and ATR structures. Known structural domains are shown for each protein, with numbers above ATR diagram indicating percent identity/similarity of primary amino acid sequence of ATR compared with that of ATM. Numbers on right of each diagram
ading frame. FAT and FATC $(C)$ domains are provide total number of amino acids for each polypeptide based on the predicted open reading frame. FAT and FATC (C) domains are aligned for ATM and ATR (see text for details on FAT domains). No significant homology was detected between the predicted FATC domains of these two proteins. The PI 3-kinase related catalytic domain (PI3Kc) is also shown for ATM (residues 2715-3011) and ATR (residues 2324-2627). The amino-terminal cross-hatched box indicates a functionally undefined region of homology between ATM (residues 1493-1773) and ATR (residues 1191-1463). Sequence alignments were performed with the CD-Search algorithm of the NCBI Blast 2 Program. (aa) Amino acids. 
Table 1. Organization of PIKK subfamilies in human and yeast cells

\begin{tabular}{llcc}
\hline Subfamily & Homo sapiens & S. cerevisiae & S. pombe \\
\hline ATM & ATM & TEL1 & tel1 \\
ATR & ATR & MEC1 & rad $^{+}$ \\
TOR & mTOR/FRAP & TOR1 & tor1 \\
& & TOR2 & tor2 \\
SMG-1 & hSMG1/ATX & - & - \\
DNA-PK & DNA-PK & - & - \\
TRRAP & TRRAP & TRA1 & tra1 \\
\hline
\end{tabular}

The organization shown is based on overall deduced amino acid sequence homology. Dashed lines indicate the absence of homologs in yeast. Sequence comparisons among the different subfamilies suggest that the members of the ATM, ATR, SMG1 , and TOR subfamilies may have diverged from a common ancestor.

teins may function as molecular scaffolds during eukaryotic gene transcription (McMahon et al. 1998).

\section{Biochemistry of the ATM and ATR kinases}

Before launching into a discussion of the roles of ATM and ATR in checkpoint signaling, it seems appropriate to review the current state of knowledge regarding their protein kinase activities, as many laboratories are actively pursuing the identification of in vivo substrates for the ATM and ATR catalytic domains. The first PIKK family member to be characterized as a protein kinase was DNA-PK (Gottlieb and Jackson 1993; Smith et al. 1999|. Like most protein kinases, partially purified preparations of DNA-PK displayed $\mathrm{Mg}^{2+}$-dependent, serine-threonine kinase activity in the presence of ATP and substrate (e.g, the transcription factor, SP1; Gottlieb and Jackson 1993; Hartley et al. 1995). Consistent with its role in signaling during DNA dsb repair, the in vitro kinase activity of DNA-PK was optimal when both enzyme and substrate were bound to the same DNA fragment (Gottlieb and Jackson 1993). In addition, the preferred target sequence for phosphorylation by DNA-PK was serine or threonine followed by glutamine at the +1 position. Hence DNA-PK is commonly identified as an "S/T-Q-directed kinase", based on the single-letter amino acid code for the consensus phosphorylation site.

The availability of ATM- and ATR-specific antibodies allowed investigators to determine whether these two PIKKs also expressed protein kinase activity, at least in the test tube. Immune complex kinase assays quickly revealed that, like DNA-PK, ATM and ATR displayed S/T-Q-directed kinase activities under in vitro conditions, and that a physiologically relevant substrate for both protein kinases was p53 (Banin et al. 1998; Canman et al. 1998; Tibbetts et al. 1999; Ziv et al. 2000). The major in vitro phosphorylation site for ATM and ATR was Ser 15, which resides in the sequence context, L $\underline{S} Q E$ (phosphorylation site is underlined). Interestingly, all of the PIKKs characterized to date, mammalian or otherwise, function as S/T-Q-directed kinases, with the no- table exception of the yeast and mammalian TOR proteins. In the case of mTOR, phosphorylation of the bestcharacterized protein substrate, PHAS-I (also termed 4E-BP1) occurs mainly at two threonine residues (Thr 36 and Thr 45) nested within duplicated STTPGG sequences (Brunn et al. 1997a,b; Gingras et al. 1999, 2001). However, mTOR fails to phosphorylate Ser 15 in p53, or S/T-Q sites in other proteins that are known targets for ATM/ATR (R.T. Abraham, unpubl.). The reader should not be confused by ATM and ATR kinase assay protocols that use PHAS-I as the substrate (e.g., Banin et al. 1998; Yang and Kastan 2000). The PHAS-I polypeptide is rich in serine and threonine residues, and, in fact, contains three S/T-Q sites, one of which (Ser 111) is phosphorylated by ATM or ATR in vitro (Yang and Kastan 2000; R.T. Abraham, unpubl.). The potential relevance of Ser 111 phosphorylation by ATM to PHAS-I function (Yang and Kastan 2000) is discussed in a later section of this review. Nonetheless, the major mTOR phosphorylation sites, Thr 36 and Thr 45, are not targeted by either ATM or ATR in immune complex kinase assays.

Two parameters related to the protein kinase assays for ATM and ATR are worthy of mention, in that both raise some cautionary notes concerning the extent to which the activities determined in vitro reflect the actual situation in intact cells. First, the protein kinase activity of ATM, but not of ATR or DNA-PK, is quite sensitive to inhibition by the nonionic detergents (e.g., Triton X-100, NP-40) commonly used to prepare whole cell or nuclear extracts (Gottlieb and Jackson 1993; Sarkaria et al. 1998, 1999; Yavuzer et al. 1998). The inhibitory effect of certain nonionic detergents on ATM kinase activity is not without precedent, in that a similar result was obtained during the initial characterization of the catalytic activity of mTOR (Brunn et al. 1997a). In both cases, the detergent problem was circumvented through substitution of Triton X-100/NP-40 with a less stringent detergent (e.g., Tween-20) in the cell lysis buffer (Brunn et al. 1997a; Banin et al. 1998; Sarkaria et al. 1998; Tibbetts et al. 1999; Ziv et. al. 2000). Although the explanation remains unclear, the inhibitory effects of nonionic detergents on ATM kinase activity may reflect either the disruption of intramolecular interactions that are required to maintain the native conformation of the catalytic domain, or the loss of regulatory protein or lipid partners during the extraction and purification process.

The protein kinase activities of ATM and ATR, as measured in immune complex kinase assays, also display unusually strong dependencies on the presence of millimolar concentrations of $\mathrm{Mn}^{2+}$ in the kinase assay buffer. Under test-tube conditions, it appears that the presence of the $\mathrm{Mn}^{2+}$-ATP complex is virtually essential for the phosphorylation of various substrates by ATM and ATR (Kim et al. 1999; Chan et al. 2000; R.T. Abraham, unpubl.). Again, this property of extreme $\mathrm{Mn}^{2+}$ dependence is shared with mTOR (Brunn et al. 1997a). The catalytic activities of many conventional protein kinases (e.g., Src family protein tyrosine kinases) are stimulated by addition of $\mathrm{Mn}^{2+}$ in lieu of $\mathrm{Mg}^{2+}$ as the ATP-binding cofactor in the kinase reaction buffer /Cooper and King 
1986). However, the fact that ATM and ATR display almost undetectable phosphotransferase activities in the presence of the physiologic phosphate donor, $\mathrm{Mg}^{2+}-\mathrm{ATP}$, does raise questions about their actual activities in intact cells. As a cofactor for phosphate transfer from ATP to substrate, $\mathrm{Mn}^{2+}$ is intrinsically far more active than is $\mathrm{Mg}^{2+}$ (Schieven and Martin 1988). Perhaps the low levels of phosphorylating activity observed in the presence of $\mathrm{Mg}^{2+}$-ATP complexes accurately reflects the fact that ATM and ATR turn over their respective protein substrates at relatively low rates in intact cells. This scenario meshes nicely with the idea that substrate phosphorylation by ATM/ATR, in the context of a DNAbound damage recognition complex, places a higher premium on spatially restricted substrate modification than on signal amplification through rapid phosphorylation of many molecules of the same target protein. An alternative and equally plausible explanation is that the processes of extraction and purification compromise the normally $\mathrm{Mg}^{2+}$-dependent kinase activity of ATM/ATR to the point where significant activity in vitro can only be visualized in the presence of $\mathrm{Mn}^{2+}$-ATP complexes.

Despite these uncertainties, recent studies have shed some meaningful light on the preferred target sequences for phosphorylation by ATM and ATR. One approach was based on the earlier finding that ATM phosphorylated the physiologically relevant substrate, p53, exclusively within the S-Q motif beginning at Ser 15 (Siliciano et al. 1997; Banin et al. 1998). Kastan and coworkers generated a panel of glutathione S-transferase (GST)-p53 fusion proteins in which the residues surrounding the ATM/ATR target site, Ser 15, were systematically varied (Kim et al. 1999). The general conclusion from these experiments was that hydrophobic or acidic residues surrounding the targeted Ser-Gln motif favored phosphorylation of the Ser residue by immunopurified ATM, whereas positively charged amino acids were inhibitory. Furthermore, ATM exhibited a strong preference for Ser over Thr as the phosphoacceptor site, at least in the context of the p53 amino-terminal sequence. A second group of investigators used an iterative peptide library screening approach to define an optimal sequence context for phosphorylation by ATM (O'Neill et al. 2000). These efforts identified a consensus phosphorylation site [(M/F)$(\mathrm{Q} / \mathrm{P})-\mathrm{L}-\mathrm{S}-\mathrm{Q}-(\mathrm{E} / \mathrm{Q})]$ that was in reasonable agreement with that defined by Kastan and coworkers (Kim et al. 1999). Remarkably, the relatively unbiased peptide selection strategy zeroed in on a core L-S-Q-E target sequence, which was identical to that surrounding the Ser 15 site in p53.

The available evidence suggests that the consensus sequence for phosphorylation by ATR overlaps extensively with that defined for ATM (Kim et al. 1999). The similarity in terms of substrate preference contrasts sharply with the differential activities of these proteins during DNA damage responses (see below for discussion). Once again, these results suggest that proximity, rather than sequence context, plays a pivotal role in the selection of those substrates that undergo phosphorylation by ATM versus ATR in response to genotoxic stress. In general, the specific activity of ATR toward most substrates in vitro is significantly lower than that displayed by ATM (Canman et al. 1998; R.S. Tibbetts and R.T. Abraham, unpubl.). One notable exception is the human checkpoint protein, hRad17, which contains two S-Q sites that are phosphorylated by both ATM and ATR in immune complex kinase assays. A peptide containing these sites was phosphorylated at a higher rate by ATR than by ATM (Kim et al. 1999), and we have found that a GSThRad17 fusion protein is a significantly better substrate for ATR than for ATM (Bao et al. 2001; R.S. Tibbetts and R.T. Abraham, unpubl.).

The identification of favorable sequence contexts for phosphorylation by ATM/ATR prompted in silico searches for candidate physiological substrates for these protein kinases (Kim et al. 1999; O'Neill et al. 2000). These database mining efforts yielded a rich harvest of checkpoint/DNA repair proteins, including p53, hRad17, hChk1, the Nijmegan breakage syndrome protein (NBS1, also termed p95 or nibrin), BRCA1, and BRCA2. Many of these early candidates have now been established as substrates for either ATM only, or both ATM and ATR. As will become apparent from the remaining sections of this review, substrate identification has become a very hot topic in the ATM/ATR field, and the search has now expanded to include novel suspects in various checkpoint signaling pathways, based, in part, on the presence of conserved S-Q target motifs in the primary sequences of these proteins.

The final, and possibly the most controversial, aspect of ATM/ATR biochemistry concerns the mechanism whereby DNA damage triggers substrate phosphorylation by these protein kinases. The standard paradigm for protein kinase signaling suggested that the stimulus (i.e., genotoxic stress) would somehow shift the ATM/ATR kinase domains from low-activity to high-activity states. This prediction held true for ATM, as the protein kinase activity of the immunoprecipitated enzyme increases several fold within $1 \mathrm{~h}$ after cellular exposure to IR or radiomimetic agents (Banin et al. 1998; Canman et al. 1998). On the other hand, our group has failed to detect any increases in the in vitro kinase activity of ATR after treatment of cells with various genotoxic agents, including IR and UV light (R.S. Tibbetts and R.T. Abraham, unpubl.). However, immunofluorescence microscopy revealed that ATR responded to DNA damage by undergoing a dramatic shift in intranuclear localization, from diffuse to focal in nature (Tibbetts et al. 2000; see below for discussion). Under identical experimental conditions, ATM did not enter into nuclear foci in cells damaged with IR or other DNA-damaging agents. Collectively, these results hint that ATM and ATR respond to DNA damage in fundamentally different fashions: One checkpoint kinase (ATM) becomes catalytically active, whereas the other (ATR) redistributes into DNA damage-induced nuclear foci, where it presumably gains access to its substrates.

As is usually the case with "simple" models, the bifurcating DNA damage response mechanism proposed earlier will undergo substantial embellishment during 
the next few years. Although immunoprecipitation of ATR from whole cell extracts provides no evidence for activation of the ATR kinase domain by genotoxic agents, it is possible that enzyme activation in fact occurs, but is restricted to the subpopulation of ATR molecules that migrates into nuclear foci. In this situation, the increase in activity may be lost in the background noise generated by immunoprecipitation of the entire extractable pool of ATR from the damaged cells. Biochemical strategies directed toward selective recovery of focally localized ATR might simultaneously enrich for the activated form of this protein kinase. Conversely, recent findings from Shiloh and coworkers suggest that ATM might also undergo relocalization to nuclear foci in response to radiomimetic agents (Andejecko et al. 2001). These ATM-containing complexes are colocalized with the phosphorylated form of histone H2AX, which suggests that they are generated in close proximity to DNA dsbs (Downs et al. 2000; Paull et al. 2000). Thus, future experiments may lead us to conclude that the early responses of ATM and ATR to DNA damage are not as mechanistically distinct as they now appear.

A major area of uncertainty surrounds the mechanism whereby IR treatment of intact cells leads to an increase in the protein kinase activity of ATM. An obvious possibility is that reactive oxygen intermediates or DNA dsbs produced during IR exposure triggers a posttranslational modification (e.g., phosphorylation) of ATM that activates the kinase domain. Interestingly, a candidate autophosphorylation site (Ser 440) has been identified in the amino-terminal region of ATM, but whether this site is actually phosphorylated in response to IR remains unknown (Kim et al. 1999). An alternative model, which has garnered some experimental support, is based on the DNA-PK paradigm. Binding of the DNA-PK holoenzyme complex to free DNA ends stimulates the activity of the DNA-PK ${ }_{\mathrm{cs}}$ subunit (Smith et al. 1999). The familial relationships among ATM, ATR, and DNA-PK prompted speculation that ATM and ATR activities might also be regulated, in a more or less direct fashion, through interactions with DNA. Subsequent studies revealed that biochemically purified ATM could be captured from solution by immobilized DNA fragments (for review, see Durocher and Jackson 2001). The association of ATM with free DNA ends was also visualized directly by atomic force microscopy (Smith et al. 1999). Similarly, studies in the Xenopus model system indicate that ATR binds to DNA, although specific DNA end-binding activity was not investigated (Guo et al. 2000). Nonetheless, these results are consistent with the notion that ATM and ATR are capable of interacting directly with DNA.

A far more contentious issue is whether single- or double-stranded DNA stimulates the rates of substrate phosphorylation by ATM and ATR in vitro. Unfortunately, several groups have recently addressed this model, and diametrically opposite results were obtained-some investigators observe DNA-dependent activation, and others do not (Guo et al. 2000; Durocher and Jackson 2001). In certain, but not all, cases (Guo et al. 2000), the apparent stimulatory effect of DNA on
ATM/ATR kinase activity may stem from the use of DNA-binding substrates, such as full-length p53 or replication protein $\mathrm{A}$. The concern here is that the effect of DNA is entirely indirect, that is, the DNA-bound form of the substrate is in a more favorable conformation for phosphorylation by the soluble ATM or ATR kinase. As discussed earlier, it might be argued that the presence of $\mathrm{Mn}^{2+}$ in the kinase assay buffers alleviates a biologically relevant dependency of ATM/ATR activity on DNA. However, Kastan and coworkers have reported that the complete replacement of $\mathrm{Mn}^{2+}$ with $\mathrm{Mg}^{2+}$ in the assay buffer fails to uncover any stimulatory effect of DNA on ATM/ATR kinase activity (Kim et al. 1999). The discrepant outcomes in these assays might be attributable to the different preparations of ATM and ATR (e.g., biochemically purified vs. immunoprecipitated protein) used by the different laboratories. Perhaps some groups copurify ATM and ATR with sheared chromosomal DNA, which causes the resulting protein kinase activities to appear refractory to stimulation by exogenously added DNA in vitro.

The strongest case for DNA-dependent activation of ATR comes from recent studies of Xatr derived from Xenopus egg extracts (Guo et al. 2000; Hekmat-Nejad et al. 2000). An intriguing enzyme purification scheme was used in one of these studies, beginning with the capture of a subpopulation of the total pool of Xatr molecules on DNA cellulose, followed by digestion of the DNA with DNase I (Guo et al. 2000). The resolubilized Xatr was then immunoprecipitated with anti-Xatr antibodies for immune complex kinase assays. Remarkably, the specific kinase activity of the DNA-binding subpopulation of Xatr molecules was 10- to 20-fold higher than that of Xatr immunoprecipitated directly from the egg cytosol. These results suggest either that binding to DNA-cellulose triggers an increase in Xatr kinase activity, or that the DNA-cellulose selectively binds to a preactivated form of Xatr.

In summary, although an increasingly compelling body of evidence argues that ATM and ATR are capable of associating directly or indirectly with DNA, the impact of DNA binding on their catalytic activities remains a matter of debate. The most parsimonious model would suggest that, like the DNA-PK holoenzyme (Smith et al. 1999|, ATM and ATR are attracted to sites of DNA damage through constitutive or inducible associations with DNA-binding regulatory subunits. Members of the Rad family of checkpoint proteins are presently the best candidates for the putative $\mathrm{Ku}$ analogs in the ATM/ATR pathway. Recent studies have identified $\operatorname{Rad} 26$ and LCD1/PIE1/DDC2 as potential regulatory subunits of the ATM/ATR homologs expressed in fission and budding yeast, respectively (Edwards et al. 1999; Paciotti et al. 2000; Rouse and Jackson 2000; Wakayama et al. 2001), and many laboratories are undoubtedly engaged in the search for the mammalian Rad26 homolog. Although there is no reason to expect that $\operatorname{Rad} 26$ itself would tether ATM/ATR to damaged DNA, it may place these protein kinases in a DNA-responsive conformation. A second potential DNA-targeting subunit is $\operatorname{Rad} 17$ (S. 
pombe nomenclature). In fission yeast, $\operatorname{rad} 17^{+}$associates with chromatin throughout the yeast cell cycle, and this basal level of DNA-bound $\operatorname{rad} 17^{+}$is either increased or decreased in response to genotoxic stress, with the direction of change determined by the type of DNA damage incurred by these cells (Griffiths et al. 2000; Kai et al. 2001). In addition to its predicted role as a checkpoint clamp loader for the Rad1-Rad9-Hus1 complex (Thelen et al. 1999; Venclovas and Thelen 2000), our group has shown that treatment of human cells with genotoxic agents triggers rapid associations of ATM and ATR with hRad17 (Bao et al. 2001). Thus, it is conceivable that chromatin-bound Rad17 might regulate the trafficking of ATM and ATR onto and off of damaged DNA in vertebrate cells. The next few years should provide a much clearer view of both the recruitment of ATM/ATR to sites of DNA damage, and of the proximal events that couple DNA damage recognition to enhanced phosphorylation of substrates by both of these protein kinases.

\section{The ATM/ATR-associated signaling machinery: complex complexes}

Like other members of the PIKK family, ATM and ATR contain very large amino-terminal domains, the functions of which are largely unknown. However, it has long been speculated that the very extended amino-termini of the PIKKs also play central roles in scaffolding these protein kinases into macromolecular signaling complexes. Indeed, gel filtration analyses indicate that both ATM and ATR are constitutive residents of very high molecular weight $\left(\mathrm{M}_{\mathrm{R}},>2 \times 10^{6} \mathrm{D}\right)$ protein complexes in mammalian cells (Wright et al. 1998; Shiloh 2001). The identification of the components of these complexes is an area of burgeoning interest, with the expected payoff being novel insights into both the upstream regulators and downstream targets of ATM and ATR in cell-cycle checkpoint pathways.

An intriguing first step toward the elucidation of the ATM- and ATR-associated signaling complexes comes from mass spectrometric analysis of anti-BRCA1 immunoprecipitates prepared from mammalian cell extracts (Wang et al. 2000). The breast cancer susceptibility protein, BRCA1, is a critical component of the checkpoint signaling and DNA repair machinery, and is a direct target for phosphorylation by ATM and ATR in cells exposed to genotoxic stress (Cortez et al. 1999; Scully and Livingston 2000; Scully et al. 2000; Tibbetts et al. 2000). The sequencing of BRCA1-associated polypeptides yielded a remarkably broad array of proteins with clear connections to checkpoints, DNA repair, and human chromosomal instability syndromes, an outcome that prompted the authors to coin the acronym BASC (BRCA1-associated genome surveillance complex) as a global descriptor for this complex (Wang et al. 2000). In addition to ATM, the members of the BASC include the mismatch repair proteins, MLH1, MSH2, and MSH6, the Bloom's syndrome helicase (BLM), and the Mre11Rad50-NBS1 complex. The latter complex plays impor- tant roles in the recombinational repair of DNA dsbs, and the loss of one of the components of this complex, NBS1, gives rise to the Nijmegen breakage syndrome, a chromosomal instability disorder that bears several similarities to A-T (Shiloh 1997). Two independent studies of BRCA1-associated proteins added components of the chromatin remodeling apparatus and the Fanconi anemia-related protein FANCD2 to an expanding list of BASC components (Bochar et al. 2000; Garcia-Higuera et al. 2001).

The identification of the BASC represents the start of a challenging but much needed effort to understand the afferent inputs that regulate ATM and ATR function, and the intermolecular interactions that control the presentation of appropriate substrates to these checkpoint kinases. It is important to recognize that the BASC is likely not a single entity, but rather a dynamic collection of protein complexes whose compositions change with the type of DNA damage, location relative to the damaged site, and time after initiating genetic insult. If BRCA1 is indeed a central scaffold for complex assembly, then it will be important to determine whether sitespecific phosphorylation of BRCA1 by ATM/ATR (Cortez et al. 1999; Tibbetts et al. 2000), hChk2 (J.S. Lee et al. 2000), and other protein kinases controls the migration of specific checkpoint and repair proteins into and out of the BASC.

A related area that requires additional investigation concerns the relationship between the biochemically defined complexes containing ATR and BRCA1, and the DNA damage-induced nuclear foci that have been observed by immunofluorescence microscopy (Scully et al. 1997; Tibbetts et al. 2000). Many of these foci react with both ATR- and BRCA1-specific antibodies, suggesting that the two proteins colocalize at sites of DNA damage. The colocalization of a checkpoint kinase with its substrate seems quite logical; however, this simple model is complicated by the recognition that, to be detected as immunofluorescent nodes, DNA damage-induced foci must contain hundreds of ATR and BRCAl polypeptides. If we assume that nuclear foci mark individual sites of DNA damage, then, in lieu of trivial explanations, such as fixation-induced structural artifacts, it becomes important to understand why each DNA lesion triggers the coalescence of so many ATR and BRCA1 polypeptides. In keeping with the potentially dynamic state of the BASC at various stages of the DNA damage response, it is plausible that a single damaged site stimulates the generation of a dynamic, interactive series of ATR-BRCA1 complexes, each comprising a subset of the BASC components described earlier.

\section{Cell-cycle checkpoint functions of ATM and ATR}

Investigations of the checkpoint signaling functions of ATM and ATR have largely followed a time-tested strategy for protein kinases, which begins with the identification of substrates and proceeds through analyses of the functional consequences of substrate phosphorylation. Before the cloning of the ATM gene, the dedicated efforts 
of many laboratories documented that ATM-deficient cells displayed significant defects in the $G_{1}, S$, and $G_{2}$ checkpoints. These observations prompted intensive searches for ATM substrates among the numerous proteins that function in each of these checkpoints. Most of these ATM targets have also been tested, in an empirical fashion, as substrates for ATR. Although the empirical approach has been rewarding, the inevitable outcome has been that the list of documented ATR substrates overlaps largely, if not entirely, with that linked to ATM. Despite the seeming overlap, the emerging picture suggests that the checkpoint signaling functions of ATM and ATR are far from redundant-a conclusion that should become apparent as we march through the $\mathrm{G}_{1}, \mathrm{~S}$, and $G_{2}$ checkpoints in the following sections.

\section{The $G_{1}$ checkpoint}

At the heart of the $G_{1}$ checkpoint lies the series of events leading to the accumulation of the tumor suppressor protein, p53. Although p53 exerts a pervasive influence on checkpoint functions during the mammalian cell cycle, the $\mathrm{G}_{1}$ checkpoint represents the only case in which loss of p53 leads to total checkpoint abrogation (Ko and Prives 1996; Giaccia and Kastan 1998; North and Hainaut 2000). DNA damage induced by most, if not all, forms of genotoxic stress induces a rapid increase in the level of p53, a response that is mediated primarily through an increase in protein stability. In addition to triggering the accumulation of p53, genotoxic stress induces posttranslational modifications that regulate the transcriptional activating functions of this protein. With respect to the $G_{1}$ checkpoint, a key target for transcriptional activation by p53 is the cyclin-dependent kinase inhibitor, p21 (also termed WAF1 or CIP1). The p53-dependent increase in p21 expression suppresses cyclin Eand cyclin A-associated cdk2 activities, and thereby prevents $G_{1}$-to-S phase progression. In addition to $\mathrm{p} 21$, the activated form of p53 stimulates the expression of a large panel of genes, which, depending on the cellular context and type of initiating insult, may modulate intracellular redox status, or induce the host cell to undergo apoptosis (Yu et al. 1999).

An intricate web of protein kinases and phosphatases, as well as histone acetylases and ubiquitin-conjugating enzymes, regulates the accumulation and transcriptional-activating functions of p53 (Ko and Prives 1996; Giaccia and Kastan 1998). A link between ATM and p53 was predicted on the basis of earlier studies, which demonstrated that A-T cells exhibited a delayed and reduced level of p53 protein induction following exposure to IR (Kastan et al. 1992; Lu and Lane 1993). The subsequent cloning of ATM allowed several groups to test the straightforward hypothesis that ATM was a direct effector of p53 phosphorylation in IR-damaged cells (Banin et al. 1998; Canman et al. 1998). These studies pinpointed a single serine residue (Ser 15) in the amino-terminal region of p53 as a phosphorylation site for the ATM kinase in vitro. Moreover, phosphorylation of Ser 15 was rapidly induced in IR-treated cells, and this response was
ATM dependent, as IR-induced Ser 15 phosphorylation was significantly, but not completely, suppressed in A-T cells (Siliciano et al. 1997; Banin et al. 1998; Canman et al. 1998). The residual phosphorylation at Ser 15 in A-T cells hinted that ATM was not the only IR-regulated Ser 15 kinase, and this suspicion was confirmed with the observation that UV-induced Ser 15 phosphorylation was virtually unimpaired in A-T cells. Subsequent studies showed that ATR was also capable of phosphorylating p53 at Ser 15 in immune complex kinase assays (Hall-Jackson et al. 1999; Lakin et al. 1999; Tibbetts et al. 1999). In cells rendered functionally deficient for ATR by overexpression of a kinase-inactive $\mathrm{ATR}^{\mathrm{KI}}$ mutant (Cliby et al. 1998), the early phase (0-2 h) of IR-induced p53 phosphorylation was not impaired, which is consistent with the idea that ATM serves as the major Ser 15 kinase during the acute response to IR (Tibbetts et al. 1999). However, the $\mathrm{ATR}^{\mathrm{KI}}$-overexpressing cells did show a significant defect in their ability to maintain phosphorylation of Ser 15 at later times, which suggests that the maintenance phase of p53 phosphorylation was more highly dependent on ATR. On the other hand, treatment of human fibroblasts with UV light triggered a Ser 15 phosphorylation response that was largely independent of ATM expression, and was strongly reduced, at all times postirradiation, by overexpression of $\mathrm{ATR}^{\mathrm{KI}}$ (Tibbetts et al. 1999).

This pattern of dual regulation of substrate phosphorylation by ATM and ATR in cells exposed to different forms of genotoxic stress has become a recurrent theme in the checkpoint-signaling field. Of the PIKK family members, ATM represents the primary responder to IRor radiomimetic agent-induced DNA damage. In the absence of ATM, or in normal cells that incur a high level of IR-induced DNA damage, ATR serves mainly as a backup kinase for ATM. On the other hand, ATR takes on the front-line signaling responsibilities when cells are challenged with other forms of genotoxic stress, such as UV light exposure or treatment with agents that interfere with DNA replication (aphidicolin, hydroxyurea; HU).

As is frequently the case, deciphering the functional consequences of p53 phosphorylation by ATM and ATR proved far more challenging than identification of the phosphorylation. The location of Ser 15 at the p53 amino terminus suggested that modification of this residue might trigger the dissociation of $\mathrm{p} 53$ from MDM2, a protein that targets p53 for ubiquitination, nuclear export, and proteosomal degradation (Freedman et al. 1999; Juven-Gershon and Oren 1999). Therefore, if the model were correct, ATM/ATR-dependent phosphorylation of Ser 15 would free 53 from its destabilizing binding partner, thereby favoring p53 accumulation. It turns out, however, that Ser 15 phosphorylation is not sufficient to disrupt the p53-MDM2 interaction; rather, this modification stimulates the transactivating function of p53 by enhancing the binding of this protein to the transcriptional coactivator, p300 (Dumaz and Meek 1999). However, these results do not rule out the possibility that phosphorylation of p53 at Ser 15 sets this protein up for a secondary modification that does modify the binding of 
MDM2 to p53, thereby inhibiting p53 degradation. Indeed, Dumaz et al. (1999) have shown that Ser 15 phosphorylation greatly enhances the subsequent phosphorylation of p53 at Ser 18 by casein kinase I, at least under test-tube assay conditions with purified proteins. The presence of phosphates at Ser 15 and Ser 18 reduces the avidity of full-length p53 for MDM2 by approximately threefold. Further studies are required to determine whether, and under what conditions, the tandem modification of p53 by ATM/ATR and casein kinase I contributes to p53 accumulation in intact cells.

Recent findings have reinforced the notion that ATM enhances p53 accumulation by triggering the release of this protein from MDM2. One mechanism for p53 stabilization involves an intermediate protein kinase, hChk2 (also named hCds1), which relays ATM-dependent signals to p53 and many other downstream target proteins in IR-damaged cells. ATM activates hChk2 by phosphorylating an amino terminal Thr residue (Thr 68) (Ahn et al. 2000; Melchionna et al. 2000), and hChk2, in turn, phosphorylates yet another amino-terminal Ser residue (Ser 20) in p53 (Chehab et al. 2000; Hirao et al. 2000; Shieh et al. 2000). Unlike the Ser 15 modification mentioned earlier, phosphorylation at Ser 20 interferes directly with the binding of p53 to MDM2, thereby favoring $\mathrm{p} 53$ accumulation in response to IR-induced DNA damage. The physiological relevance of hChk2 in the regulation of p53 is supported by the finding that lossof-function mutations in hChk2 can give rise to a variant form of Li-Fraumeni syndrome, a heritable, cancer-prone disorder typically associated with germ-line mutations in p53 (Bell et al. 1999).

It now seems likely that ATM also targets the p53MDM2 interaction via direct modification of the partner protein, MDM2 (Maya et al. 2001). In this report, the authors followed a circuitous but rewarding line of investigation, which began with the identification of antiMDM2 antibody epitopes that governed the ability of MDM2 to target p53 for degradation. These efforts uncovered a carboxy-terminal motif that contained the now-familiar S-Q target sequence, and Ser 395 in this sequence was identified as a phosphorylation site for ATM, both in vitro and in intact cells. It appears that Ser 395 phosphorylation favors stabilization of p53 by interfering with the shuttling activity of MDM2, which normally exports p53 out of the nucleus for proteosomal degradation in the cytoplasm.

These findings demonstrate that ATM establishes multiple regulatory contacts with p53 during the activation of the $\mathrm{G}_{1}$ checkpoint by DNA dsbs (Fig. 3). In contrast, the potential role of ATR in the activation of the $\mathrm{G}_{1}$ checkpoint by any form of genotoxic stress remains relatively obscure. It is conceivable that a parallel ATRChk1 pathway also drives p53 accumulation in cells that have incurred IR or UV light-induced DNA damage. Definitive answers to this and many other questions await the development of an ATR-deficient cell line that retains an intact $G_{1}$ checkpoint. For the time being, the real action with respect to ATR begins with the entry of cells into $S$ phase.

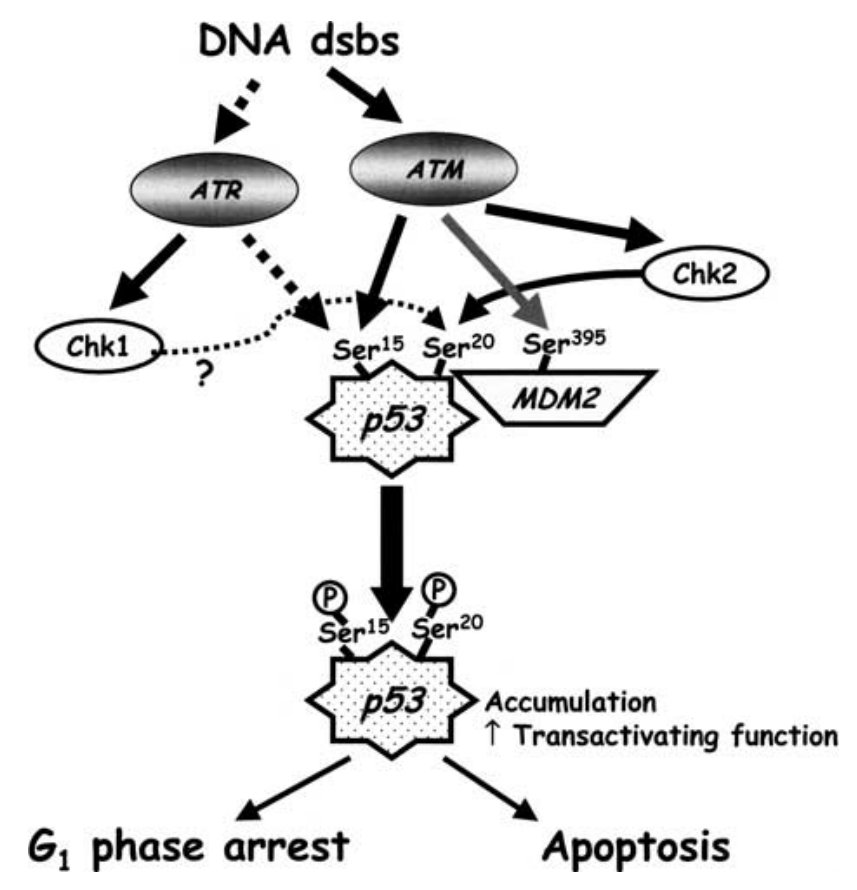

Figure 3. ATM/ATR-dependent signaling through the $\mathrm{G}_{1}$ checkpoint. Cells that have incurred DNA double-strand breaks (dsbs) during $\mathrm{G}_{1}$ phase activate p53 primarily via an ATM-dependent pathway. In cells that express both ATM and ATR, the activation of $\mathrm{p} 53$ is reinforced and maintained by ATR (pathway indicated by dotted lines). ATM regulates p53 accumulation by indirect pathways involving the Chk2-mediated phosphorylation of Ser 20 on p53, by promoting casein kinase-I-dependent phosphorylation of Ser 18 (not shown), and by directly phosphorylating MDM2 on Ser 395 (see text for details). ATR may influence Ser 20 phosphorylation through activation of Chk1.

\section{The S-phase checkpoint}

During DNA replication, mammalian cells must be on high alert for DNA structural abnormalities, such as strand breaks or base modifications that interfere with the accurate copying of the genome. In addition to the usual array of environmental insults, the process of DNA replication itself adds intrinsic risks, such as base misincorporation errors and stalled replication forks, which demand an immediate response from the checkpoint machinery if genome integrity is to be preserved. Fortunately, DNA damage detected during $S$ phase is apt to be repaired precisely via homologous recombination mechanisms involving sister chromatids (Johnson and Jasin 2000). Indeed, studies in bacteria suggest that S phase cells rely heavily on homologous recombination to restart stalled replication forks, even in the absence of genotoxic agents (Cox 1999; Cox et al. 2000). Nonhomologous repair mechanisms also play very prominent roles in DNA dsb repair during all phases of the cell cycle; however, these mechanisms are inherently less precise, and therefore confer an increased risk that inaccurately repaired DNA will be carried forward into $M$ phase. Although the $\mathrm{G}_{2}$ checkpoint should, in principle, catch any cells that have exited $S$ phase with damaged 
DNA, these cells may have already missed their best opportunity to perform error-free repair via homologous recombination.

Given this state of affairs, it comes as no surprise that the S-phase checkpoint is considerably more multifaceted than this blanket descriptor implies (Fig. 4). The canonical checkpoint defect displayed by A-T cells is radioresistant DNA synthesis (RDS; Painter and Young 1980). In normal cells, exposure to IR provokes a rapid but reversible decrease in DNA synthesis, which reflects decreases in the rates of both replication origin firing and DNA strand elongation (Painter and Young 1980). In the absence of ATM, the IR-induced decrease in DNA synthesis is dampened significantly, giving rise to the RDS phenotype. Treatment of cells with wortmannin, at drug concentrations that abrogate ATM kinase activity, also induces RDS in normal (ATM-proficient) cells (Sarkaria et al. 1998). Although loss of ATM function is causally related to RDS, the downstream effectors in this S-phase pathway checkpoint pathway have largely eluded identification, that is, until very recently. An intriguing report now shows that the surveillance functions of the
ATM-hChk2 pathway are not confined to $G_{1}$ phase (Falck et al. 2001). IR exposure during $S$ phase activates the same pathway, except that, in this setting, an important outcome is the degradation of Cdc25A, a protein tyrosine phosphatase that activates cyclin A.cdk2 complexes as cells transit from $G_{1}$ to $S$ phase. The results obtained by Falck et al. (2001) show that hChk2 phosphorylates Ser 123 in Cdc25A, and that this modification targets Cdc25A for ubiquitin-dependent degradation. The down-regulation of Cdc25A interferes with the timely activation of cyclin A.cdk2, which is a requisite event for the firing of early origins of replication during S phase (Donaldson and Blow 1999; Takisawa et al. 2000). Genetic manipulations that disrupt any step in the pathway from hChk2 to cyclin A.cdk2 also give rise to the RDS phenotype. Remarkably, mutant hChk2 alleles associated with a variant form of Li-Fraumeni syndrome (Bell et al. 1999) failed to bind and/or phosphorylate Cdc25A (Falck et al. 2001), which implies that genetic lesions in the RDS pathway promote genome instability and cancer development.

As is usually the case in signal transduction research,

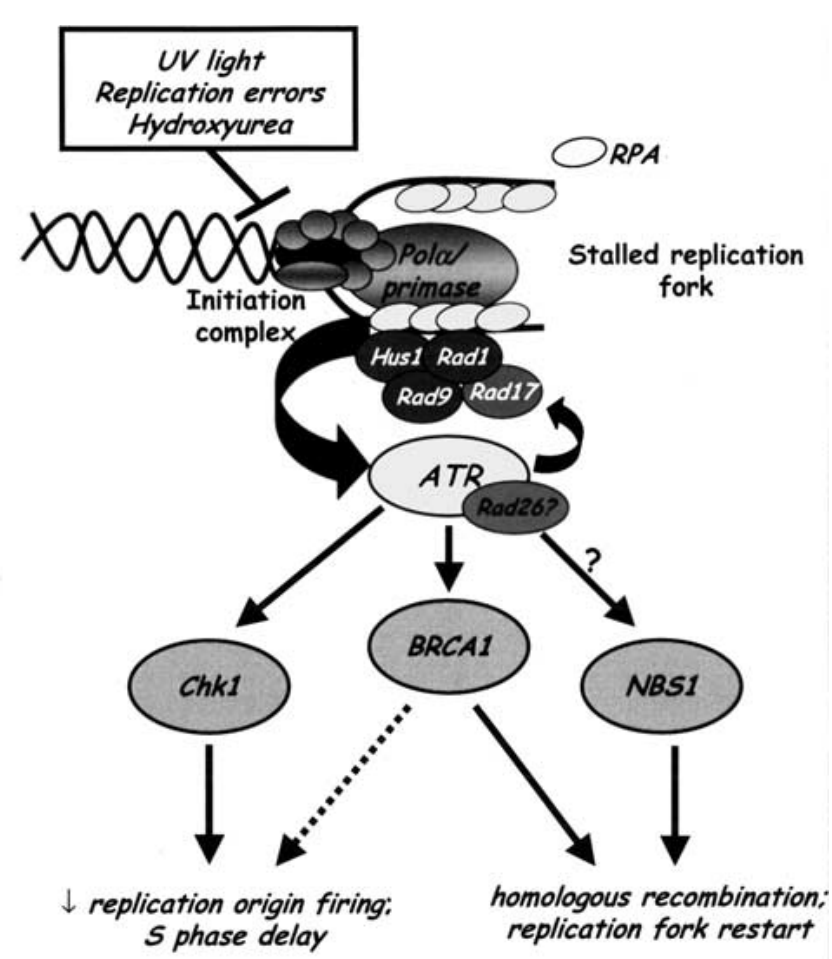

\section{Inhibition of DNA synthesis}

Figure 4. Roles of ATM and ATR in signaling through S-phase checkpoints. The ATM-dependent pathway shown in the left panel is initiated by the presence of a DNA dsb in an S-phase cell. The checkpoint response leads to the proteosome-mediated degradation of Cdc25A, and, in turn, the failure to maintain activation of cyclin.cdk2 complexes and a resultant inhibition of DNA synthesis. Disruption of this pathway yields the radioresistant DNA synthesis (RDS) phenotype. In the right panel, the checkpoint pathway is triggered by intrinsic events or environmental insults that impair replication fork progression during $\mathrm{S}$ phase. The pathway is governed primarily by ATR, and may use members of the Rad family of checkpoint proteins as damage sensors and as scaffolds for the assembly of checkpoint signaling complexes. The operation of this pathway prevents mitotic catastrophe that results from incomplete or inaccurate DNA replication, and orchestrates high-fidelity DNA repair through homologous recombination. Complete loss of this pathway is likely incompatible with viability, even in the absence of genotoxic agent-induced DNA damage. 
the simple linear pathway outlined earlier almost certainly oversimplifies the actual situation in vivo. Overexpression of the previously described $\mathrm{ATR}^{\mathrm{KI}}$ mutant in SV40-transformed (but ATM-positive) human fibroblasts also induces RDS (Cliby et al. 1998). With the caveat in mind that overexpressed $\mathrm{ATR}^{\mathrm{KI}}$ may nonspecifically cross-inhibit ATM function, these results suggest either that ATR also resides upstream of hChk2, or that ATR regulates a parallel pathway that contributes to the suppression of DNA synthesis in IR-damaged cells. By analogy to the p53 phosphorylation mechanism discussed earlier, it will be interesting to determine whether the down-regulation of Cdc25A by UV light (Mailand et al. 2000) or HU (if this occurs) is mediated predominantly through an ATR-dependent pathway, perhaps via an alternative avenue involving the hChk1 kinase.

A second participant in the DNA damage-induced Sphase checkpoint is NBS1 (also termed nibrin), the product of the gene mutated in the human chromosomal instability disorder, NBS (Shiloh 1997; Carney 1999; Petrini 1999). The clinical features of NBS show considerable but not complete overlap with those displayed by A-T patients. Interestingly, NBS cells also display the RDS phenotype, which suggests that the NBS1 protein is an upstream regulator of Cdc25A stability in IR-treated cells. The NBS1 protein is found in a complex with two other genome maintenance proteins, Mre11 and Rad50, which play important roles in the recombinational repair of DNA dsbs. Treatment of cells with IR induces the rapid formation of nuclear foci containing the NBS1Mre11-Rad50 complex, and a technologically elegant study offered strong evidence that the foci assemble in close proximity to DNA dsbs (Nelms et al. 1998). The appearance of these foci is dependent on the expression of NBS1; however, the absence of major DNA repair defects in cells from NBS patients indicates that the Mre11-Rad50 complex carries out its repair functions quite capably in NBS1-deficient cells (Petrini 1999). The overlapping clinical phenotypes of A-T and NBS prompted speculation that the two proteins might be functionally interconnected. This prediction was validated by reports that ATM phosphorylates NBS1 on up to three serine residues (Ser 343, Ser 397, and Ser 615), and that Ser $\rightarrow$ Ala substitutions at any one of these sites generated a mutant NBS1 protein that failed to complement the checkpoint defects in NBS cells /Gatei et al. 2000b; Lim et al. 2000; Wu et al. 2000; Zhao et al. 2000). At present, we do not understand the exact roles of these phosphorylation events in the function of NBS1. Nonetheless, the functional linkage between ATM and the NBS1-Mre11-Rad50 complex becomes even more compelling with the discovery that hypomorphic Mre11 alleles give rise to an A-T-like disorder in humans (Stewart et al. 1999).

The connection between S-phase checkpoint proteins and human disease does not end with the NBS1-MRE11Rad50 complex. Recent findings position ATM and ATR as critical upstream modulators of the breast cancer susceptibility protein, BRCA1, which was discussed previ- ously as the central component of the BASC (Wang et al. 2000). Accumulating evidence suggests that BRCA1 is a critically important caretaker of the replicating genome in vertebrate cells. Like the NBS1 complex, BRCA1 participates in both checkpoint and repair pathways in DNA-damaged cells (Scully and Livingston 2000; Scully et al. 2000; Xu et al. 2001). Studies of the DNA damage responses in BRCA1-deficient cells are focusing increasing attention on the role of BRCA1 in promoting highfidelity DNA repair through homologous recombination between sister chromatids (Moynahan et al. 1999; Scully et al. 2000).

Several groups have documented that BRCA1 is phosphorylated in vitro on multiple sites by the ATM and ATR kinases (Cortez et al. 1999; Chen 2000; Gatei et al. 2000a; Tibbetts et al. 2000). The carboxy-terminal region of BRCA1 contains numerous S-Q motifs (total of 14), and, of these potential ATM/ATR target sequences, 10 are localized in an $\sim 300$ amino acid stretch (residues 1250-1550) termed the SQ cluster domain (SCD) (Cortez et al. 1999). Cortez et al. (1999) observed that the phosphorylation of BRCA1 in IR-damaged cells was significantly impaired in the absence of ATM, and demonstrated that at least five of the predicted S-Q target sites in the SCD were phosphorylated by ATM in vitro. Three of these sites, Ser 1387, Ser 1423, and Ser 1524, were identified as major IR-induced phosphorylation sites in intact cells (Cortez et al. 1999; Gatei et al. 2000a). Finally, a BRCA1 double mutant containing Ala substitutions at Ser 1423 and Ser 1524 showed a modest impairment in terms of its ability to correct the radiosensitive phenotype of a BRCA1-deficient breast cancer cell line (HCC1937). The finding that ATM is an upstream regulator of BRCA1 is consistent with the highly publicized, but hotly debated, finding that human ATM heterozygotes are at increased risk for the development of breast cancer (Meyn 1999). As is the case for p53, ATM makes indirect as well as direct connections to BRCA1. Once again, the indirect pathway proceeds through the ATMregulated checkpoint kinase, hChk2 (J.S. Lee et al. 2000). Phosphorylation of BRCA1 at a single site (Ser 988) by hChk2 terminates an IR-stimulated interaction between these two proteins in cell nuclei, and is also required for the radioprotective effect of ectopically expressed BRCA1 in the HCC1937 cell line mentioned earlier.

The earlier studies clearly hinted that at least one additional BRCA1-directed kinase was activated by DNAdamaging agents, because significant BRCA1 phosphorylation was observed in cells that lacked either ATM or DNA-PK (Scully et al. 1997; Cortez et al. 1999; Tibbetts et al. 2000). ATR was the obvious suspect, and subsequent studies showed that ATR phosphorylated the carboxyl terminus of BRCA1 at six Ser/Thr residues in immune complex kinase assays (Tibbetts et al. 2000). The ATR phosphorylation sites partially overlapped with those modified in vitro by ATM. Studies with phosphoSer 1423-specific antibodies indicate that ATM and ATR share responsibilities for the modification of BRCA1 during IR-, UV-, and replication inhibitor-induced genotoxic 
stress. As is the case with p53, BRCA1 phosphorylation induced by IR was strongly dependent on ATM, whereas the phosphorylation of this protein in UV- or HU-damaged cells was more heavily reliant on ATR (Tibbetts et al. 2000). Given the complexity of the BRCA1 phosphorylation response, and the pleiotropic functions of this tumor suppressor in checkpoint signaling, BASC assembly, protein ubiquitination, and homologous recombination (Lorick et al. 1999; Scully et al. 2000; Wang et al. 2000), a complete understanding of the interplay between the checkpoint kinases and BRCAl could take quite some time.

BRCA1 is the archetypal member of a family of checkpoint repair proteins that contain the conserved BRCA1 carboxy-terminal (BRCT) structural motif (Callebaut and Mornon 1997). In addition to BRCA1, another member of this BRCT domain-containing family has recently been identified as a substrate for ATM, and likely ATR as well. The p53 binding protein 1 (53BP1) is a nuclear protein that rapidly localizes to sites of DNA damage in cells treated with IR and other DNA-damaging agents (Schultz et al. 2000; Rappold et al. 2001). This protein contains numerous Ser/Thr-Gln sites, and is phosphorylated by ATM in vitro (Rappold et al. 2001). In intact cells, the phosphorylation of 53BP1 increases rapidly after IR exposure, and this response is partially dependent on the expression of ATM, with ATR acting as the presumptive p53BP1 kinase in ATM-deficient cells (Rappold et al. 2001). Although the function of p53BP1 is unclear, it has been speculated that this protein is a homolog of the S. cerevisiae Rad9p and S. pombe Crb2 proteins, which play important roles in multiple DNA damage-induced checkpoints in these microorganisms (Elledge 1996). If 53BP1 is indeed the vertebrate counterpart of yeast Rad9p/Crb2, this protein could be an ATM/ ATR substrate of paramount relevance to checkpoint signaling throughout the cell cycle. The results of DNA damage response experiments with 53BP1-deficient cells are eagerly anticipated.

To digress a bit, the importance of understanding the molecular machinery that drives the various S-phase checkpoint pathways cannot be overstated. Proliferating cells must traverse $S$ phase, and, in spite of the magnificent accuracy of the DNA replication apparatus, the sheer magnitude of the task of DNA replication dictates that errors will inevitably occur with each pass through $S$ phase. If uncorrected, these errors, and the resultant loss of replication fidelity, may not only lead to the nucleotide sequence alterations and gross chromosomal rearrangements traditionally associated with cellular transformation, but may also favor the aberrant expansion and contraction of repetitive DNA sequences. Compelling results implicate instability of triplet repeat DNA sequences in the pathogenesis of neurodegenerative diseases (Kroutil and Kunkel 1998). The strong connections between DNA replication fidelity and human disease warrant an intensive effort to define both the checkpoint and repair mechanisms that ensure the accuracy with which the genome is duplicated during $S$ phase.

\section{The $\mathrm{G}_{2}$ checkpoint}

The final gatekeeper that blocks the entry of DNA-damaged cells into mitosis is the $\mathrm{G}_{2}$ checkpoint. Although we now have a relatively detailed view of the distal events that link this checkpoint pathway to the machinery that controls mitotic entry (for review, see O'Connell et al. 2000), the contributions of ATM and ATR to the early stages of $G_{2}$ checkpoint activation remain far less clear. Studies of the $G_{2}$ checkpoint in A-T cells led to some confusing results, at least until the emergence of ATR as a parallel initiator of checkpoint signaling. When A-T cells are exposed to IR during $G_{1}$ or $S$ phase, any cells that reach $\mathrm{G}_{2}$ phase are effectively arrested before they initiate mitosis. In fact, these cells show a more protracted $\mathrm{G}_{2}$ arrest than do ATM-expressing cells. On the other hand, if A-T cells are irradiated while in $G_{2}$ phase, then the cells fail to arrest, and proceed on into mitosis (Beamish and Lavin 1994; Scott et al. 1994). These results indicate that ATM is dispensable for activation of checkpoint-mediated $G_{2}$ arrest, unless the DNA damage occurs during $\mathrm{G}_{2}$ itself.

The ATM-independent pathway that initiates $G_{2}$ arrest in cells that have experienced a genotoxic insult before $G_{2}$ phase has not been defined. However, it seems virtually certain that ATR and Chk1 will be central players in this alternative pathway of $\mathrm{G}_{2}$ checkpoint activation. Accumulating evidence supports the idea that ATR is primarily responsible for the activation of the Chk1 kinase by DNA damaging agents in vertebrate cells. Studies in the Xenopus model system identified 4 S/T-Q sites in Xchk1 that were phosphorylated by ATR in vitro, and whose modification in oocyte extracts was ATR-dependent (Guo et al. 2000). Moreover, mutated Xchk1 containing Ser $\rightarrow$ Ala substitutions at all four sites failed to complement the DNA replication checkpoint defect in extracts that were depleted of endogenous Xchk1. Similarly, overexpression of a kinase-inactive ATR ${ }^{\mathrm{KI}}$ mutant inhibited DNA damage-induced hChk1 phosphorylation in a human fibroblast cell line (Liu et al. 2000).

The regulatory linkage between ATR and Chk1 strongly implicates ATR as a proximal component of the DNA damage-induced $G_{2}$ checkpoint in mammalian cells. Studies in yeast have defined an elegant mechanism for the negative regulation of mitotic entry by Chk1, and the fundamental characteristics of this pathway seem to be conserved during vertebrate evolution (Peng et al. 1997; Sanchez et al. 1997; O'Connell et al. 2000). The current model posits that DNA damage leads to the activation of Chk1, which, in turn, phosphorylates the mitosis-promoting phosphatase, Cde25C. Phosphorylation of Cdc25C by hChk1 creates a binding site for 14-3-3 proteins, and, in the 14-3-3-bound form, Cdc25C is either catalytically inhibited or sequestered in the cytoplasm (or both). In any case, the phosphorylated, 14-3-3-bound form of Cdc25C is prohibited from dephosphorylating and activating the mitotic cyclin B.Cdc2 kinase, and the damaged cells are effectively blocked from entering mitosis. The critical role of Chk1 in the implementation of the $G_{2}$ checkpoint is underscored by the 
finding that $C h k 1^{-/-}$embryonic stem cells display a substantial reduction in $\mathrm{G}_{2}$ arrest following IR exposure (Liu et al. 2000). The $\mathrm{G}_{2}$ checkpoint model outlined in Figure 5 tentatively inserts ATR as the upstream activator of hChk1 in human cells.

In light of the ATR-Chk1 pathway outlined earlier, how do we explain the fact the ATM-deficient cells fail to activate the $\mathrm{G}_{2}$ checkpoint when DNA damage occurs during $G_{2}$ phase? One possibility is that ATM also contributes to the inhibition of Cdc25C activity, particularly in IR-damaged cells, by activating Chk2, which is capable of phosphorylating Ser 216 of Cdc25C, at least in vitro (Brown et al. 1999). In cells that express both ATM and ATR, ATM may activate Chk2 to reinforce the block to cyclin B.Cdc2 activation imposed by the ATR-hChk1 pathway. A defect in the maintenance of the checkpointinduced $\mathrm{G}_{2}$ arrest has been observed in Chk2 $2^{-/-}$embryonic stem cells (Hirao et al. 2000). Hence, the ATMChk2 pathway may play a secondary role in $\mathrm{G}_{2}$ checkpoint activation when cells incur DNA dsbs during $G_{1}$ or $S$ phase. On the other hand, the cell cycle phase-specific defect in $G_{2}$ checkpoint function observed in ATM-null cells suggests that ATM is essential for $G_{2}$ checkpoint activation after cells have traversed $G_{1}$ and $S$ phase. The failure of ATR to engage the $G_{2}$ checkpoint machinery in cells that have completed DNA replication suggests that the sensor and/or effector apparatus through which ATR operates is fully functional only during $S$ phase.

The switch to ATM dependence for $\mathrm{G}_{2}$ checkpoint activation when DNA damage occurs in $G_{2}$ phase also raises a provocative correlation with the rise to prominence of homologous recombination as the major mode of DNA dsb repair. Studies in the DT40 chicken B cell line indicate that DNA-PK-dependent NHEJ serves as the major mode of DNA dsb repair during $G_{1}$ and early $S$ phase, whereas homologous recombination assumes center stage in late $S$ and $G_{2}$ phases (Takata et al. 1998). A later report from the same research group provided genetic evidence that ATM and the late $S-G_{2}$ recombinational repair mechanism resided in the same genome maintenance pathway (Morrison et al. 2000). The authors disrupted either the homologous recombination pathway (via targeted deletion of the Rad54 gene) or the NHEJ pathway (via targeted deletion of the Ku70 gene) in $A T M^{-/-}$DT40 cells. Whereas loss of the recombinational repair pathway marginally increased the incidence of IRinduced chromosome aberrations in the $A T M^{-/-}$cells, Ku70 deficiency dramatically enhanced both the chromosomal damage and radiosensitivity of the ATM-deficient cells. The synergistic increase in IR-induced chromosomal abnormalities observed in ATM/Ku70 doublydeficient cells suggested that the ATM-dependent repair

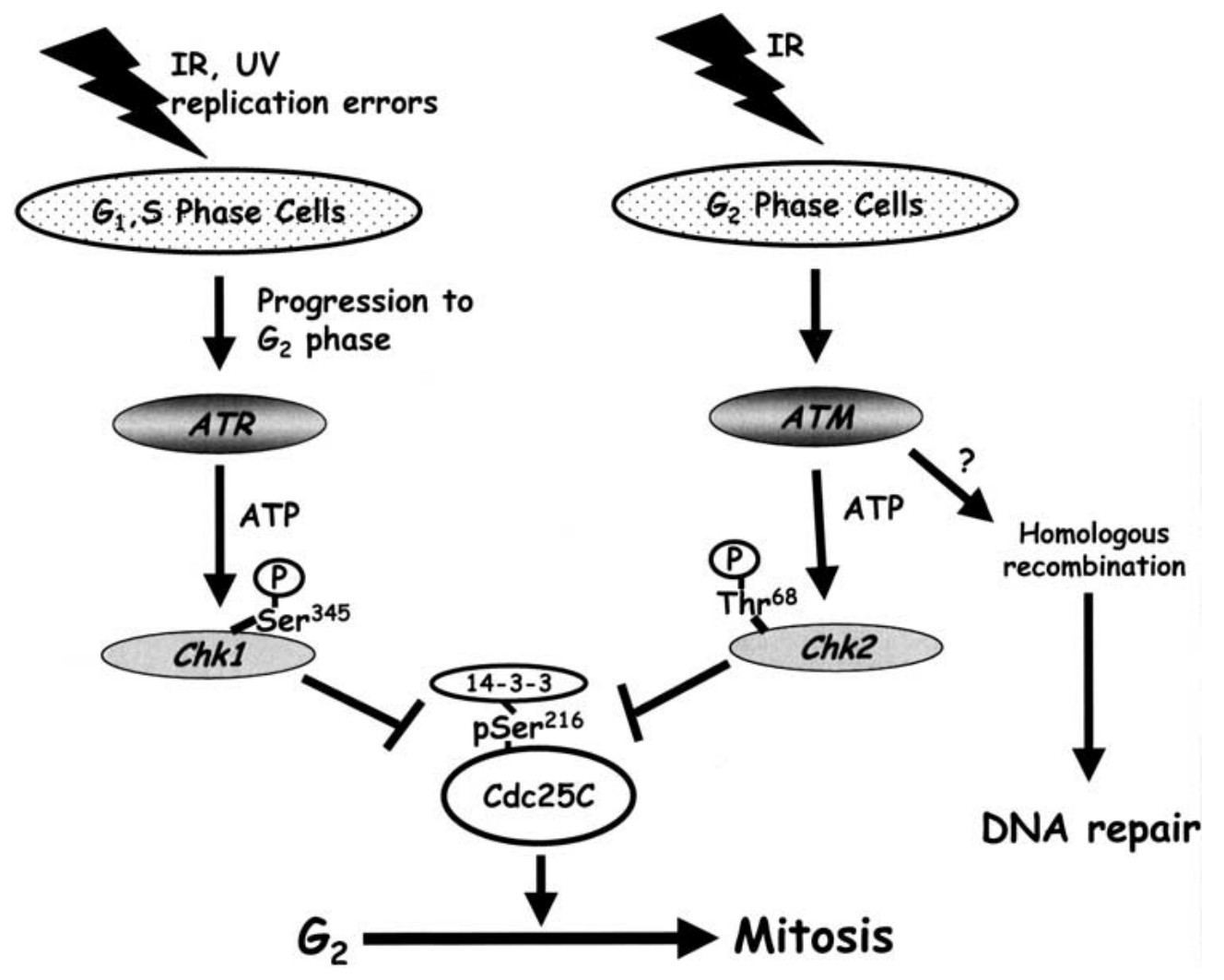

Figure 5. Roles of ATM and ATR in $\mathrm{G}_{2}$ checkpoint activation. The left branch of this pathway is activated when cells incur DNA damage before completion of $S$ phase, and is governed primarily by ATR. The right branch of the pathway is activated by DNA damage during the $\mathrm{G}_{2}$ phase itself, and depends largely on the activation of ATM. Both branches converge on the Cdc25C phosphatase, and prevent activation of the mitotic cyclin B.cdc2 complex by inducing the cytoplasmic sequestration and/or catalytic inhibition of Cdc25C. 
pathway (presumably homologous recombination) and the Ku70-dependent repair pathway (NHEJ) act in a complementary fashion to restore chromosomal integrity after IR exposure. Although these studies provide solid evidence for functional ties between ATM and the homologous recombination pathway, a major uncertainty surrounds the nature of this relationship. The connection could be very direct; for example, phosphorylation of one or more members of the homologous recombination pathway by ATM. Alternatively, the available evidence does not exclude the possibility that loss of ATM-dependent checkpoint functions indirectly impairs the ability of the homologous recombination machinery to accurately repair DNA dsbs.

\section{Extranuclear targets for ATM?}

Although early studies of the subcellular distribution of ATM were plagued with questions surrounding the specificities of the anti-ATM antibodies, the presence of ATM in the cytoplasm of certain cell types, particularly neurons, is now well documented (Barlow et al. 2000). The expression of cytoplasmic ATM has prompted speculation that the signaling functions of this PIKK family member may not be restricted solely to the nucleus. One as yet unproven hypothesis holds that cytoplasmic ATM responds to certain genotoxic insults, such as an increase in reactive oxygen intermediates, and coordinates cytoplasmic responses with the nuclear events associated with checkpoint activation. A protective role for cytoplasmic ATM against oxygen-derived free radicals is consistent with the notion that A-T patients, and the cells derived from these patients, show signs of chronic oxidative stress (Rotman and Shiloh 1997).

The subject of extranuclear functions for ATM has stirred particular interest with respect to the devastating neurodegenerative pathologies associated with A-T (Crawford 1998). Young A-T patients invariably suffer from progressive neuronal cell death that initially affects the cerebellar Purkinje neurons. Interestingly, Purkinje cells contain a substantial pool of cytoplasmic ATM (Barlow et al. 2000). Neurons in general are notoriously sensitive to oxidative stress, and undergo apoptosis when exposed to an unmanageable level of reactive oxygen intermediates in vitro. These observations have fostered speculation that cytoplasmic ATM protects Purkinje neurons from oxidative stress by stimulating antioxidant defenses in the host cells. The induction of NF-кB-dependent genes by ATM could represent one such antioxidant defense mechanism (Jung et al. 1995, 1997), although another group has disputed the evidence for a direct linkage between ATM and NF-кB activation (Ashburner et al. 1999).

A provocative model for the neuroprotective functions of ATM has emerged from studies of insulin/insulin-like growth factor (IGF) receptors in nonneuronal cells. The authors show that insulin stimulation triggers a rapid increase in ATM kinase activity in human embryonic kidney cells, and provide evidence that a physiologic tar- get for ATM is the translational repressor protein PHASI/4E-BP1 (Yang et al. 2000). The authors propose that ATM-dependent phosphorylation of PHAS-I at Ser 111 phosphorylation sets the stage for subsequent phosphorylations at Thr 69 and Ser 64, which are mediated by mTOR or other protein kinases (Gingras et al. 1999; Mothe-Satney et al. 2000). These events culminate in the release of PHAS-I/4E-BP1 from the translation initiation factor, eIF-4E, and the stimulation of cap-dependent translation (Gingras et al. 2001). Although further work is required to fully document these results (for discussion, see Lavin 2000), the unexpected implication is that ATM plays a direct role in insulin/IGF-stimulated protein synthesis. This scenario positions ATM as a relatively proximal component of the insulin/IGF-1-dependent signaling pathways leading to critical cellular responses, ranging from glucose uptake and metabolism, to cell growth and survival. Given the preliminary evidence that a similar pathway may be present in neuronal cells (Yang et al. 2000), it is conceivable that ATM is an important transducer of survival-promoting signals from IGF receptors in CNS neurons. In A-T patients, defects in IGF and insulin responsiveness could contribute to both the neurodegeneration and the occurrence of insulin-resistant diabetes in a subpopulation of A-T patients.

The proposed linkage between ATM and IGF receptor signaling was further tightened with the recent finding that intracellular ATM positively regulates the expression of IGF-1 receptors at the level of gene transcription (Peretz et al. 2001). Fibroblasts from A-T patients were shown to exhibit depressed levels of IGF-1 receptor protein, and this defect was corrected by transfection of these cells with an expression vector encoding wild-type ATM. Most importantly, forced expression of IGF-1 receptors in A-T fibroblasts reduced the radiosensitivity of these cells to a level similar to that observed in their ATM-transfected counterparts. If these findings can be extrapolated to CNS neurons, then defects in IGF-1 receptor expression could be a major contributor to the various neuropathologies associated with the A-T syndrome. It would be of interest to examine cell lines from NBS patients for similar defects in IGF-1 receptor expression and IGF-1-dependent radioprotection. As discussed previously, the ATM and NBS1 proteins appear to lie in the same checkpoint pathway, and the clinical features of A-T partially overlap with those of NBS1 (Shiloh 1997). However, cerebellar neurodegeneration is not a prominent feature of NBS. If loss of NBS1 fails to suppress IGF-1 receptor expression, then we could tentatively conclude that the stimulatory effect of ATM on IGF-1 promoter activity is not obligatorily linked to its role in DNA dsb-induced signaling. Whatever the outcome, the available data strongly argue that further investigations of the impact of ATM deficiency on IGF-1 receptor expression and signaling functions could radically alter current concepts regarding the pathogenesis and treatment of A-T.

As intriguing as the ATM-IGF-1 receptor connections seem, other findings provide equally strong support for the concept that defective DNA damage responses pre- 
dispose A-T patients to premature neurodegeneration (Rolig and McKinnon 2000). These studies began with the finding that neurons from ATM-deficient mice displayed, quite unexpectedly, a heightened level of resistance to killing by IR (Herzog et al. 1998). Subsequently, it was shown that mice deficient in DNA ligase IV, an enzyme required for the nonhomologous end-joining pathway of DNA dsb repair, died in utero due to massive apoptosis of the developing central nervous system (CNS) neurons. Crossing of these $\mathrm{Lig} 4^{-/-}$mice onto the ATM nullizygous background results in a dramatic rescue of both the embryonic lethality, and the apoptotic death of CNS neurons (Y. Lee et al. 2000). These results suggest that, during early CNS development, ATM functions as a caretaker that marks genetically damaged neurons for elimination, at a time when their healthy cohorts can readily replace them. In the absence of ATM, damaged neurons are neither eliminated nor replaced, and, postpartum, these functionally compromised cells are destined to undergo an early demise in the brains of young A-T patients. If this model is correct, then definitive therapy aimed toward the prevention of neurodegeneration in A-T patients could be very difficult, as it would need to be initiated during gestation.

\section{Conclusions}

The identification of the full-length cDNAs encoding ATM and ATR ushered in an explosive era of research focused on cell-cycle checkpoint signaling in mammalian cells. Without a doubt, much of the recent progress in this area rests squarely on the shoulders of elegant studies performed in genetically tractable model systems, particularly fission and budding yeast. The conservation of many of the core components of checkpoint signaling pathways, as well as of the cell-cycle apparatus itself, has facilitated efforts to define the mechanisms through which mammalian cells guard the integrity of their genomes. A general model for the division of labor between ATM and ATR is emerging from work performed primarily in mammalian cells and Xenopus egg extracts. In a sense, ATR might be considered the housekeeping member of this duo, in that genome maintenance during normal cell proliferation hinges on the surveillance functions of ATR. The early embryonic lethality induced by $A T R$ gene disruption may reflect the breakdown of both the DNA replication checkpoint, and the checkpoint responses to overt DNA damage incurred during S phase (Brown and Baltimore 2000; de Klein et al. 2000).

ATR also plays a central role in the response to certain types of genotoxic agents, including hydroxyurea and UV light. Again, we can draw a clear link to S phase, as cells are normally alerted to the lesions induced by these agents when deoxyribonucleotide depletion or abnormal DNA structures impede the progress of advancing replication forks. In this regard, it is intriguing that the binding of ATR to DNA and the activation of the replication checkpoint require RNA primer synthesis by DNA polymerase- $\alpha$ (Hekmat-Nejad et al. 2000; Michael et al.
2000). A synthesis of the available data suggests that ATR might play a critical role in the $S$ and $G_{2}$ checkpoints /although additional functions in the $M$-phase checkpoint should not be discounted), and ATM might assume primary responsibility for management of the $G_{1}$ checkpoint.

In contrast to ATR, ATM seems dedicated to providing the cell with a rapid protective response to an extremely lethal form of DNA damage, the DNA dsb. Although ATM research has focused heavily on the response to IR-induced DNA dsbs, it is likely that, outside of the laboratory setting, the intrinsic accoutrements of life as a multicellular organism, such as continuous assaults by oxygen-derived radicals, and the need to generate a diverse repertoire of antigen-responsive lymphocytes, generated evolutionary pressure for the development of a checkpoint signaling module geared toward sounding the DNA dsb alarm at the first sign of trouble. The identification of ATM as a key regulator of p53 in cells that have incurred DNA dsbs not only links ATM to the $G_{1}$ checkpoint, but also suggests that ATM participates directly in making life and death decisions in certain cell types, particularly thymocytes and early-stage neurons. In A-T patients, disruption of the p53-dependent pathways that would normally direct irreparably damaged cells to undergo apoptosis during embryonic or early postnatal life may sow the seeds for the neurodegeneration and cancer predisposition that are so characteristic of this disease. An intriguing possibility, which demands additional attention, is that ATM plays a more general role in cytoprotection against oxidative stress, possibly by inducing the expression of NFкB-regulated genes ( $\mathrm{Li}$ et al. 2001).

Finally, considerable interest has developed in the area of drug discovery related to ATM, ATR, and other checkpoint proteins. Small molecule inhibitors of these proteins would undoubtedly find widespread applications at the laboratory bench, as investigators continue to dissect the contributions of these protein kinases to various signaling pathways, checkpoint or otherwise. However, the real impetus for drug discovery in this area rests on the notion that specific inhibitors of ATM and ATR, and of their downstream target proteins, might find clinical applications, particularly in the treatment of cancer. A central premise of modern cancer cell biology is that cancer development is a hyperevolutionary process fueled by genetic instability (Hartwell and Kastan 1994; Weinert 1997; Lengauer et al. 1998; Cahill et al. 1999). A major mechanism whereby tumor cells acquire genetic instability is through the acquisition of mutations that weaken or eliminate cell-cycle checkpoints. Loss of checkpoint controls is particularly prevalent in the later stages of cancer development, and it is these tumor cells that tend to be especially refractory to killing by conventional anticancer agents, many of which either damage DNA directly or interfere with DNA replication. Perhaps pharmacologic inhibitors of ATM and/or ATR would allow clinical oncologists to beat tumor cells at their game. On a background of compromised checkpoints, it is conceivable that combined therapy with, for 
example, an inhibitor of DNA synthesis (e.g., 5-fluorouracil or gemcitibine) and an ATR kinase inhibitor would drive checkpoint-compromised tumor cells into a premature, lethal mitosis, while sparing nonmalignant cells, which retain the full complement of cell-cycle checkpoints. The finding that caffeine, an inhibitor of mammalian ATM and ATR (Sarkaria et al. 1999), selectively sensitizes p53-deficient tumor cells to killing by IR lends credibility to this therapeutic strategy (Powell et al. 1995; Yao et al. 1996). The discovery of highly specific inhibitors of ATM and ATR, and their successful application to the therapy of human cancer, would make the long journey through checkpoint signaling pathways a rewarding one indeed.

\section{Acknowledgments}

I thank Drs. Sally Kornbluth, Kathy Brumbaugh, Chris Hudson, and the anonymous reviewers for helpful comments regarding the manuscript. Work in the author's laboratory is supported by a grant from the National Cancer Institute (CA76193), and by grants from the A-T Children's Project and the Johnson \& Johnson Focused Giving Program.

\section{References}

Abraham, R.T. and Wiederrecht, G.J. 1996. Immunopharmacology of rapamycin. Annu. Rev. Immunol. 14: 483-510.

Ahn, J.Y., Schwarz, J.K., Piwnica-Worms, H., and Canman, C.E. 2000. Threonine 68 phosphorylation by ataxia telangiectasia mutated is required for efficient activation of Chk2 in response to ionizing radiation. Cancer Res. 60: 5934-5936.

Andejecko Y., Moyal, L., Mittelman, L., Tsarfaty, I., Shiloh, Y., and Rotman, G. 2001. Nuclear retention of ATM at sites of DNA double strand breaks. J. Biol. Chem. (in press).

Ashburner, B.P., Shackelford, R.E., Baldwin, A.S., and Paules, R.S. 1999. Lack of involvement of ataxia telangiectasia mu-

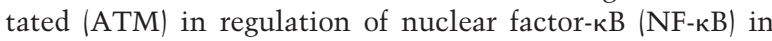
human diploid fibroblasts. Cancer Res. 59: 5456-5460.

Banin, S., Moyal, L., Shieh, S., Taya, Y., Anderson, C.W., Chessa, L., Smorodinsky, N.I., Prives, C., Reiss, Y., Shiloh, Y., et al. 1998. Enhanced phosphorylation of p53 by ATM in response to DNA damage. Science 281: 1674-1677.

Bao S., Tibbetts, R.S., Brumbaugh, K.M., Fang, Y., Richardson, D.A., Ali, A., Chen, S.M., Abraham, R.T., and Wang X.-F. 2001. ATR/ATM mediated phosphorylation of human Rad17 is required for genotoxic stress responses. Nature 411: 969-974.

Barlow, C., Ribaut-Barassin, C., Zwingman, T.A., Pope, A.J., Brown, K.D., Owens, J.W., Larson, D., Harrington, E.A., Haeberle, A.M., Mariani, J., et al. 2000. ATM is a cytoplasmic protein in mouse brain required to prevent lysosomal accumulation. Proc. Natl. Acad. Sci. 97: 871-876.

Beamish, H. and Lavin, M.F. 1994. Radiosensitivity in ataxiatelangiectasia: Anomalies in radiation-induced cell cycle delay. Int. J. Radiat. Biol. 65: 175-184.

Bell, D.W., Varley, J.M., Szydlo, T.E., Kang, D.H., Wahrer, D.C., Shannon, K.E., Lubratovich, M., Verselis, S.J., Isselbacher, K.J., Fraumeni, J.F., et al. 1999. Heterozygous germ line hCHK2 mutations in Li-Fraumeni syndrome. Science 286: $2528-2531$

Bochar, D.A., Wang, L., Beniya, H., Kinev, A., Xue, Y., Lane, W.S., Wang, W., Kashanchi, F., and Shiekhattar, R. 2000.
BRCA1 is associated with a human SWI/SNF-related complex: Linking chromatin remodeling to breast cancer. Cell 102: 257-265.

Bosotti, R., Isacchi, A., and Sonnhammer, E.L. 2000. FAT: A novel domain in PIK-related kinases. Trends Biochem. Sci. 25: 225-227.

Brown, A.L., Lee, C.H., Schwarz, J.K., Mitiku, N., PiwnicaWorms, H., and Chung, J.H. 1999. A human Cds1-related kinase that functions downstream of ATM protein in the cellular response to DNA damage. Proc. Natl. Acad. Sci. 96: 3745-3750.

Brown, E.J. and D. Baltimore. 2000. ATR disruption leads to chromosomal fragmentation and early embryonic lethality. Genes \& Dev. 14: 397-402.

Brown, E.J., Albers, M.W., Shin, T.B., Ichikawa, K., Keith, C.T., Lane, W.S., and Schreiber, S.L. 1994. A mammalian protein targeted by the G1-arresting rapamycin-receptor complex. Nature 369: 756-758.

Brunn, G.J., Hudson, C.C., Sekulic, A., Williams, J.M., Hosoi, J., Houghton, P.J., Lawrence, J.C., and Abraham, R.T. 1997a. Phosphorylation of the translational repressor PHAS-I by the mammalian target of rapamycin. Science 277: 99-101.

Brunn, G.J., Fadden, P., Haystead, T.A.J., and Lawrence, J.C.J. 1997b. The mammalian target of rapamycin phosphorylates sites having a (Ser/Thr)-Pro motif and is activated by antibodies to a region near its $\mathrm{COOH}$ terminus. J. Biol. Chem. 272: 32547-32550.

Burtelow, M.A., Kaufmann, S.H., and Karnitz, L.M. 2000. Retention of the human Rad9 checkpoint complex in extraction-resistant nuclear complexes after DNA damage. J. Biol. Chem. 275: 26343-26348.

Cafferkey, R., McLaughlin, M.M., Young, P.R., Johnson, R.K., and Livi G.P. 1994. Yeast TOR (DRR) proteins: Amino-acid sequence alignment and identification of structural motifs. Gene 141: 133-136.

Cahill, D.P., Kinzler, K.W., Vogelstein, B., and Lengauer, C. 1999. Genetic instability and darwinian selection in tumours. Trends Biochem. Sci. 24: 57-60.

Callabaut, I. and Mornon J.P. 1997. From BRCA1 to RAP1: A widespread BRCT module closely associated with DNA repair. FEBS Lett. 400: 25-30.

Canman, C.E., Lim, D.S., Cimprich, K.A., Taya, Y., Tamai, K., Sakaguchi, K., Appella, E., Kastan, M.B., and Siliciano, J.D. 1998. Activation of the ATM kinase by ionizing radiation and phosphorylation of p53. Science 281: 1677-1679.

Carney, J.P. 1999. Chromosomal breakage syndromes. Curr Opin. Immunol. 11: 443-447.

Chan, D.W., Son, S.C., Block, W., Ye, R., Khanna, K.K., Wold, M.S., Douglas, P., Goodarzi, A.A., Pelley, J., Taya, Y., et al. 2000. Purification and characterization of ATM from human placenta. A manganese-dependent, wortmannin-sensitive serine/threonine protein kinase. J. Biol. Chem. 275: 7803 7810.

Chehab, N.H., Malikzay, A., Appel, M., and Halazonetis, T.D. 2000. Chk2/hCds1 functions as a DNA damage checkpoint in $\mathrm{G}_{1}$ by stabilizing p53. Genes \& Dev. 14: 278-288.

Chen, J. 2000. Ataxia telangiectasia-related protein is involved in the phosphorylation of BRCA1 following deoxyribonucleic acid damage. Cancer Res. 60: 5037-5039.

Cimprich, K.A., Shin, T.B., Keith, C.T., and Schreiber, S.L. 1996. cDNA cloning and gene mapping of a candidate human cell cycle checkpoint protein. Proc. Natl. Acad. Sci. 93: 2850-2855.

Cliby, W.A., Roberts, C.J., Cimprich, K.A., Stringer, C.M., Lamb, J.R., Schreiber, S.L., and Friend, S.H. 1998. Overexpression of a kinase-inactive ATR protein causes sensitivity 
to DNA-damaging agents and defects in cell cycle checkpoints. EMBO J. 17: 159-169.

Cooper, J.A. and King, C.S. 1986. Dephosphorylation or antibody binding to the carboxy terminus stimulates pp60c-src. Mol. Cell. Biol. 6: 4467-4477.

Cortez, D., Wang, Y., Qin, J., and Elledge, S.J. 1999. Requirement of ATM-dependent phosphorylation of BRCA1 in the DNA damage response to double-strand breaks. Science 286: $1162-1166$

Cox, M.M. 1999. Recombinational DNA repair in bacteria and the RecA protein. Prog. Nucleic Acid Res. Mol. Biol. 63: 311-366.

Cox, M.M., Goodman, M.F., Kreuzer, K.N., Sherratt, D.J., Sandler, S.J., and Marians, K.J. 2000. The importance of repairing stalled replication forks. Nature 404: 37-41.

Crawford, T.O. 1998. Ataxia telangiectasia. Semin. Pediatr. Neurol. 5: 287-294.

de Klein, A., Muijtjens, M., van Os, R., Verhoeven, Y., Smit, B., Carr, A.M., Lehmann, A.R., and Hoeijmakers, J.H. 2000. Targeted disruption of the cell-cycle checkpoint gene ATR leads to early embryonic lethality in mice. Curr. Biol. 10: 479482.

Denning, G., Jamieson, L., Maquat, L.E., Thompson, L.A., and Fields, A.P. 2001. Cloning of a novel phosphatidylinositol kinase-related kinase. J. Biol. Chem. 276: 22709-22714.

Donaldson, A.D. and Blow, J.J. 1999. The regulation of replication origin activation. Curr. Opin. Genet. Dev. 9: 62-68.

Downs, J.A., Lowndes, N.F., and Jackson, S.P. 2000. A role for Saccharomyces cerevisiae histone H2A in DNA repair. $\mathrm{Na}$ ture 408: 1001-1004.

Dumaz, N. and Meek, D.W. 1999. Serine15 phosphorylation stimulates p53 transactivation but does not directly influence interaction with HDM2. EMBO J. 18: 7002-7010.

Dumaz, N., Milne D.M., and Meek D.W. 1999. Protein kinase $\mathrm{CK} 1$ is a p53-threonine 18 kinase which requires prior phosphorylation of serine 15. FEBS Lett. 463: 312-316.

Durocher, D. and Jackson, S.P. 2001. DNA-PK, ATM and ATR as sensors of DNA damage: Variations on a theme? Curr. Opin. Cell Biol. 13: 225-231.

Edwards, R.J., Bentley, N.J., and Carr, A.M. 1999. A Rad3-Rad26 complex responds to DNA damage independently of other checkpoint proteins. Nat. Cell Biol. 1: 393-398.

Elledge, S.J. 1996. Cell cycle checkpoints: Preventing an identity crisis. Science 274: 1664-1672.

Falck, J., Mailand, N., Syljuasen, R.G., Bartek, J., and Lukas, J. 2001. The ATM-Chk2-Cdc25A checkpoint pathway guards against radioresistant DNA synthesis. Nature 410: 842-847.

Freedman, D.A., Wu, L., and Levine, A.J. 1999. Functions of the MDM2 oncoprotein. Cell. Mol. Life Sci. 55: 96-107.

Garcia-Higuera, I., Taniguchi, T., Ganesan, S., Meyn, M.S. Timmers, C., Hejna, J., Grompe, M., and D'Andrea, A.D. 2001. Interaction of the fanconi anemia proteins and BRCA1 in a common pathway. Mol. Cell 7: 249-262.

Gatei, M., Scott, S.P., Filippovitch, I., Soronika, N., Lavin, M.F., Weber, B., and Khanna, K.K. 2000a. Role for ATM in DNA damage-induced phosphorylation of BRCA1. Cancer Res. 60: 3299-3304.

Gatei, M., Young, D., Cerosaletti, K.M., Desai-Mehta, A., Spring, K., Kozlov, S., Lavin, M.F., Gatti, R.A., Concannon, P., and Khanna, K. 2000b. ATM-dependent phosphorylation of nibrin in response to radiation exposure. Nat. Genet. 25: 115-119.

Giaccia, A.J. and Kastan, M.B. 1998. The complexity of p53 modulation: Emerging patterns from divergent signals. Genes \& Dev. 12: 2973-2983.

Gingras, A.C., Gygi, S.P., Raught, B., Polakiewicz, R.D., Abra- ham, R.T., Hoekstra, M.F., Aebersold, R., and Sonenberg, N. 1999. Regulation of 4E-BP1 phosphorylation: A novel twostep mechanism. Genes \& Dev. 13: 1422-1437.

Gingras, A.C., Raught, B., and Sonenberg, N. 2001. Regulation of translation initiation by FRAP/mTOR. Genes \& Dev. 15: $807-826$.

Gottlieb, T.M. and Jackson, S.P. 1993. The DNA-dependent protein kinase: Requirement for DNA ends and association with $\mathrm{Ku}$ antigen. Cell 72: 131-142.

Grant, P.A., Schieltz, D., Pray-Grant, M.G., Yates III, J.R., and Workman, J.L. 1998. The ATM-related cofactor Tral is a component of the purified SAGA complex. Mol. Cell 2: 863867.

Green, C.M., Erdjument-Bromage, H., Tempst, P., and Lowndes, N.F. 2000. A novel Rad24 checkpoint protein complex closely related to replication factor C. Curr. Biol. 10: 39-42.

Griffiths, D., Uchiyama, M., Nurse, P., and Wang, T.S.F. 2000. A novel mutant allele of the chromatin-bound fission yeast checkpoint protein Rad17 separates the DNA structure checkpoints. J. Cell Sci. 113: 1075-1088.

Guo, Z.J., Kumagai, A., Wang, S.X., and Dunphy, W.G. 2000. Requirement for Atr in phosphorylation of Chk1 and cell cycle regulation in response to DNA replication blocks and UV-damaged DNA in Xenopus egg extracts. Genes \& Dev. 14: 2745-2756.

Hall-Jackson, C.A., Cross, D.A., Morrice, N., and Smythe, C. 1999. ATR is a caffeine-sensitive, DNA-activated protein kinase with a substrate specificity distinct from DNA-PK. Oncogene 18: 6707-6713.

Hartley, K.O., Gell, D., Smith, G.C., Zhang, H., Divecha, N., Connelly, M.A., Admon, A., Lees-Miller, S.P., Anderson, C.W., and Jackson, S.P. 1995. DNA-dependent protein kinase catalytic subunit: A relative of phosphatidylinositol 3 -kinase and the ataxia telangiectasia gene product. Cell 82: 849-856.

Hartwell, L.H. and Kastan, M.B. 1994. Cell cycle control and cancer. Science 266: 1821-1828.

Hekmat-Nejad, M., You, Z.S., Yee, M.C., Newport, J.W., and Cimprich, K.A. 2000. Xenopus ATR is a replication-dependent chromatin-binding protein required for the DNA replication checkpoint. Curr. Biol. 10: 1565-1573.

Helliwell, S.B., Wagner, P., Kunz, J., Deuter-Reinhard, M., Henriquez, R., and Hall, M.N. 1994. TOR1 and TOR2 are structurally and functionally similar but not identical phosphatidylinositol kinase homologues in yeast. Mol. Biol. Cell 5: $105-118$.

Herzog, K.H., Chong, M.J., Kapsetaki, M., Morgan, J.I., and McKinnon, P.J. 1998. Requirement for Atm in ionizing radiation-induced cell death in the developing central nervous system. Science 280: 1089-1091.

Hirao, A., Kong, Y.Y., Matsuoka, S., Wakeham, A., Ruland, J., Yoshida, H., Liu, D., Elledge, S.J., and Mak, T.W. 2000. DNA damage-induced activation of $\mathrm{p} 53$ by the checkpoint kinase Chk2. Science 287: 1824-1827.

Hunter, T. 1995. When is a lipid kinase not a lipid kinase? When it is a protein kinase. Cell 83: 1-4.

Johnson, R.D. and Jasin, M. 2000. Sister chromatid gene conversion is a prominent double-strand break repair pathway in mammalian cells. EMBO J. 19: 3398-3407.

Jung, M., Zhang, Y., Lee, S., and Dritschilo, A. 1995. Correction of radiation sensitivity in ataxia telangiectasia cells by a truncated I к B- $\alpha$. Science 268: 1619-1621.

Jung, M., Kondratyev, A., Lee, S.A., Dimtchev, A., and Dritschilo, A. 1997. ATM gene product phosphorylates I $\kappa$ B- $\alpha$. Cancer Res. 57: 24-27.

Juven-Gershon, T. and Oren, M. 1999. Mdm2: The ups and 
downs. Mol. Med. 5: 71-83.

Kai, M., Tanaka, H., and Wang, T.S.F. 2001. Fission yeast Rad17 associates with chromatin in response to aberrant genomic structures. Mol. Cell. Biol. 21: 3289-3301.

Kastan, M.B., Zhan, Q., el-Deiry, W.S., Carrier, F., Jacks, T., Walsh, W.V., Plunkett, B.S., Vogelstein, B., and Fornace, Jr., A.J. 1992. A mammalian cell cycle checkpoint pathway utilizing p53 and GADD45 is defective in ataxia-telangiectasia. Cell 71: 587-597.

Kim, S.T., Lim, D.S., Canman, C.E., and Kastan, M.B. 1999. Substrate specificities and identification of putative substrates of ATM kinase family members. J. Biol. Chem. 274: 37538-37543.

Ko, L.J. and Prives, C. 1996. p53: Puzzle and paradigm. Genes \& Dev. 10: 1054-1072.

Kroutil, L.C. and Kunkel, T.A. 1998. DNA replication errors involving strand misalignments. In Genetic instabilities and hereditary neurological diseases (eds. R.D. Wells and S.T. Warren), pp. 699-716. Academic Press, San Diego, CA.

Lakin, N.D., Hann, B.C., and Jackson, S.P. 1999. The ataxiatelangiectasia related protein ATR mediates DNA-dependent phosphorylation of p53. Oncogene 18: 3989-3995.

Lavin, M.F. 2000. An unlikely player joins the ATM signalling network. Nat. Cell Biol. 2: E215-E217.

Lee, J.S., Collins, K.M., Brown, A.L., Lee, C.H., and Chung, J.H. 2000. hCds1-mediated phosphorylation of BRCA1 regulates the DNA damage response. Nature 404: 201-204.

Lee, Y., Barnes, D.E., Lindahl, T., and McKinnon, P.J. 2000. Defective neurogenesis resulting from DNA ligase IV deficiency requires Atm. Genes \& Dev. 14: 2576-2580.

Lengauer, C., Kinzler, K.W., and Vogelstein, B. 1998. Genetic instabilities in human cancers. Nature 396: 643-649.

Li, N.X., Banin, S., Quyang, H.H., Li, G.C., Courtois, G., Shiloh, Y., Karin, M., and Rotman, G. 2001. ATM is required for I $k$ B kinase (IKK) activation in response to DNA double strand breaks. J. Biol. Chem. 276: 8898-8903.

Lim, D.S., Kim, S.T., Xu, B., Maser, R.S., Lin, J., Petrini, J.H., and Kastan, M.B. 2000. ATM phosphorylates p95/nbs1 in an Sphase checkpoint pathway. Nature 404: 613-617.

Liu, Q., Guntuku, S., Cui, X.S., Matsuoka, S., Cortez, D., Tamai, K., Luo, G., Carattini-Rivera, S., DeMayo, F., Bradley, A., et al. 2000. Chk1 is an essential kinase that is regulated by Atr and required for the $\mathrm{G}_{2} / \mathrm{M}$ DNA damage checkpoint. Genes \& Dev. 14: 1448-1459.

Lorick, K.L., Jensen, J.P., Fang, S., Ong, A.M., Hatakeyama, S., and Weissman, A.M. 1999. RING fingers mediate ubiquitinconjugating enzyme (E2)-dependent ubiquitination. Proc. Natl. Acad. Sci. 96: 11364-11369.

Lowndes N.F. and Murguia, J.R. 2000. Sensing and responding to DNA damage. Curr. Opin. Genet Dev. 10: 17-25.

$\mathrm{Lu}, \mathrm{X}$. and Lane, D.P. 1993. Differential induction of transcriptionally active p53 following UV or ionizing radiation: Defects in chromosome instability syndromes? Cell 75: 765778.

Mailand, N., Falck, J., Lukas, C., Syljuasen, R.G., Welcker, M., Bartek, J., and Lukas, J. 2000. Rapid destruction of human Cdc25A in response to DNA damage. Science 288: 14251429.

Maquat, L.E. 2000. Nonsense-mediated mRNA decay in human cells: A splicing-dependent means to downregulate the levels of mRNAs that prematurely terminate translation. In Translational control of gene expression (eds. N. Sonenberg, J.W.B. Hershey, and M.B. Mathews), pp. 849-868. Cold Spring Harbor Laboratory Press, Cold Spring Harbor, NY.

Maya, R., Balass, M., Kim, S.-T., Shkedy, D., Leal, J.-F.M., Shifman, O., Moas, M. Buschmann, T., Ronai, Z., Shiloh, Y., et al. 2001. ATM-dependent phosphorylation of Mdm2 on serine 395: Role in p53 activation by DNA damage. Genes \& Dev. 15: 1067-1077.

McMahon, S.B., Van Buskirk, H.A., Dugan, K.A., Copeland, T.D., and Cole, M.D. 1998. The novel ATM-related protein TRRAP is an essential cofactor for the c-Myc and E2F oncoproteins. Cell 94: 363-374.

Melchionna, R., Chen, X.B., Blasina, A., and McGowan, C.H. 2000. Threonine 68 is required for radiation-induced phosphorylation and activation of Cds1. Nat. Cell Biol. 2: 762765.

Meyn, M.S. 1999. Ataxia-telangiectasia, cancer and the pathobiology of the ATM gene. Clin. Genet. 55: 289-304.

Michael, W.M., Ott, R., Fanning, E., and Newport, J. 2000. Activation of the DNA replication checkpoint through RNA synthesis by primase. Science 289: 2133-2137.

Morrison, C., Sonoda, E., Takao, N., Shinohara, A., Yamamoto, K., and Takeda, S. 2000. The controlling role of ATM in homologous recombinational repair of DNA damage. $E M B O$ J. 19: 463-471.

Mothe-Satney, I., Yang, D., Fadden, P., Haystead, T.A., and Lawrence, Jr., J.C. 2000. Multiple mechanisms control phosphorylation of PHAS-I in five $(\mathrm{S} / \mathrm{T}) \mathrm{P}$ sites that govern translational repression. Mol. Cell. Biol. 20: 3558-3567.

Moynahan, M.E., Chiu, J.W., Koller, B.H., and Jasin, M. 1999. Brcal controls homology-directed DNA repair. Mol. Cell 4: $511-518$.

Nelms, B.E., Maser, R.S., MacKay, J.F., Lagally, M.G., and Petrini, J.H. 1998. In situ visualization of DNA double-strand break repair in human fibroblasts. Science 280: 590-592.

North, S. and Hainaut, P. 2000. p53 and cell-cycle control: A finger in every pie. Pathol. Biol. 48: 255-270.

O'Connell, M.J., Walworth, N.C., and Carr, A.M. 2000. The G2-phase DNA-damage checkpoint. Trends Cell Biol. 10: 296-303.

O’Neill, T., Dwyer, A.J., Ziv, Y., Chan, D.W., Lees-Miller, S.P., Abraham, R.T., Lai, J.H., Hill, D., Shiloh, Y., Cantley, L.C., et al. 2000. Utilization of oriented peptide libraries to identify substrate motifs selected by ATM. I. Biol. Chem. 275: 22719-22727.

Paciotti, V., Clerici, M., Lucchini, G., and Longhese, M.P. 2000. The checkpoint protein Ddc2, functionally related to $S$. pombe Rad26, interacts with Mec1 and is regulated by Mec1-dependent phosphorylation in budding yeast. Genes \& Dev. 14: 2046-2059.

Painter, R.B. and Young, B.R. 1980. Radiosensitivity in ataxiatelangiectasia: A new explanation. Proc. Natl. Acad. Sci. 77: 7315-7317.

Paull, T.T., Rogakou, E.P., Yamazaki, V., Kirchgessner, C.U., Gellert, M., and Bonner, W.M. 2000. A critical role for histone $\mathrm{H} 2 \mathrm{AX}$ in recruitment of repair factors to nuclear foci after DNA damage. Curr. Biol. 10: 886-895.

Peng, C.Y., Graves, P.R., Thoma, R.S., Wu, Z., Shaw, A.S., and Piwnica-Worms, H. 1997. Mitotic and G2 checkpoint control: Regulation of 14-3-3 protein binding by phosphorylation of Cdc25C on serine-216. Science 277: 1501-1505.

Peretz, S., Jensen, R., Baserga, R., and Glazer, P.M. 2001. ATMdependent expression of the insulin-like growth factor-1 receptor in a pathway regulating radiation response. Proc. Natl. Acad. Sci. 98: 1676-1681.

Petrini, J.H. 1999. The mammalian Mre11-Rad50-nbs1 protein complex: Integration of functions in the cellular DNA-damage response. Am. J. Hum. Genet. 64: 1264-1269.

Powell, S.N., DeFrank, J.S., Connell, P., Eogan, M., Preffer, F., Dombkowski, D., Tang, W., and Friend, S. 1995. Differential sensitivity of p53(-) and p53(+) cells to caffeine-induced ra- 
diosensitization and override of G2 delay. Cancer Res. 55: 1643-1648.

Rappold, I., Iwabuchi, K., Date, T., and Chen, J. 2001. Tumor suppressor p53 binding protein 1 (53BP1) is involved in DNA damage signaling pathways. J. Cell Biol. 153: 613-620.

Rogakou, E.P., Boon, C., Redon, C., and Bonner, W.M. 1999. Megabase chromatin domains involved in DNA doublestrand breaks in vivo. J. Cell Biol. 146: 905-916.

Rolig, R.L. and McKinnon, P.J. 2000. Linking DNA damage and neurodegeneration. Trends Neurosci. 23: 417-424.

Rotman, G. and Shiloh, Y. 1997. Ataxia-telangiectasia: Is ATM a sensor of oxidative damage and stress? Bioessays 19: $911-$ 917.

Rouse, J. and Jackson, S.P. 2000. LCD1: An essential gene involved in checkpoint control and regulation of the MEC1 signalling pathway in Saccharomyces cerevisiae. EMBO I. 19: $5801-5812$.

Sabatini, D.M., Erdjument-Bromage, H., Lui, M., Tempst, P., and Snyder, S.H. 1994. RAFT1: A mammalian protein that binds to FKBP12 in a rapamycin-dependent fashion and is homologous to yeast TORs. Cell 78: 35-43.

Sabers, C.J., Martin, M.M., Brunn, G.J., Williams, J.M., Dumont, F.J., Wiederrecht, G., and Abraham, R.T. 1995. Isolation of a protein target of the FKBP12-rapamycin complex in mammalian cells. J. Biol. Chem. 270: 815-822.

Sanchez, Y., Wong, C., Thoma, R.S., Richman, R., Wu, Z., Piwnica-Worms, H., and Elledge, S.J. 1997. Conservation of the Chk1 checkpoint pathway in mammals: Linkage of DNA damage to $\mathrm{Cdk}$ regulation through Cdc25. Science 277: 1497-1501.

Sarkaria, J.N., Tibbetts, R.S., Busby, E.C., Kennedy, A.P., Hill, D.E., and Abraham, R.T. 1998. Inhibition of phosphoinositide 3-kinase related kinases by the radiosensitizing agent wortmannin. Cancer Res. 58: 4375-4382.

Sarkaria, J.N., Busby, E.C., Tibbetts, R.S., Roos, P., Taya, Y., Karnitz, L.M., and Abraham, R.T. 1999. Inhibition of ATM and ATR kinase activities by the radiosensitizing agent, caffeine. Cancer Res. 59: 4375-4382.

Savitsky, K., Bar-Shira, A., Gilad, S., Rotman, G., Ziv, Y., Vanagaite, L., Tagle, D.A., Smith, S., Uziel, T., Sfez, S., et al. 1995. A single ataxia telangiectasia gene with a product similar to PI-3 kinase. Science 268: 1749-1753.

Schieven, G. and Martin, G.S. 1988. Nonenzymatic phosphorylation of tyrosine and serine by ATP is catalyzed by manganese but not magnesium. J. Biol. Chem. 263: 15590-15593.

Schultz, L.B., Chehab, N.H., Malikzay, A., and Halazonetis, T.D. 2000. p53 binding protein 1 (53BP1) is an early participant in the cellular response to DNA double strand breaks. J. Cell Biol. 151: 1381-1390.

Scott, D., Spreadborough, A.R., and Roberts, S.A. 1994. Radiation-induced G2 delay and spontaneous chromosome aberrations in ataxia-telangiectasia homozygotes and heterozygotes. Int. J. Radiat. Biol. 66: S157-S163.

Scully, R. and Livingston, D.M. 2000. In search of the tumoursuppressor functions of BRCA1 and BRCA2. Nature 408: 429-432.

Scully, R., Chen, J., Ochs, R.L., Keegan, K., Hoekstra, M., Feunteun, J., and Livingston, D.M. 1997. Dynamic changes of BRCA1 subnuclear location and phosphorylation state are initiated by DNA damage. Cell 90: 425-435.

Scully, R., Puget, N., and Vlasakova, K. 2000. DNA polymerase stalling, sister chromatid recombination and the BRCA genes. Oncogene 19: 6176-6183.

Shieh, S.Y., Ahn, J., Tamai, K., Taya, Y., and Prives, C. 2000. The human homologs of checkpoint kinases Chk1 and Cds1 (Chk2) phosphorylate p53 at multiple DNA damage-induc- ible sites. Genes \& Dev. 14: 289-300.

Shiloh, Y. 1997. Ataxia-telangiectasia and the Nijmegen breakage syndrome: Related disorders but genes apart. Annu. Rev. Genet. 31: 635-662.

. 2001. ATM and ATR: Networking cellular responses to DNA damage Curr. Opin. Genet. Dev. 11: 71-77.

Siliciano, J.D., Canman, C.E., Taya, Y., Sakaguchi, K., Appella, E., and Kastan, M.B. 1997. DNA damage induces phosphorylation of the amino terminus of p53. Genes \& Dev. 11: 34713481.

Smith, G.C.M. and Jackson, S.P. 1999. The DNA-dependent protein kinase. Genes \& Dev. 13: 916-934.

Smith, G.C., Cary, R.B., Lakin, N.D., Hann, B.C., Teo, S.H., Chen, D.J., and Jackson, S.P. 1999. Purification and DNA binding properties of the ataxia-telangiectasia gene product ATM. Proc. Natl. Acad. Sci. 96: 11134-11139.

Stewart, G.S., Maser, R.S., Stankovic, T., Bressan, D.A., Kaplan, M.I., Jaspers, N.G., Raams, A., Byrd, P.J., Petrini, J.H., and Taylor, A.M. 1999. The DNA double-strand break repair gene hMRE11 is mutated in individuals with an ataxia-telangiectasia-like disorder. Cell 99: 577-587.

Stocker, H. and Hafen, E. 2000. Genetic control of cell size. Curr. Opin. Genet. Dev. 10: 529-535.

Takata, M., Sasaki, M.S., Sonoda, E., Morrison, C, Hashimoto, M., Utsumi, H., Yamaguchi-Iwai, Y., Shinohara, A., and Takeda, S. 1998. Homologous recombination and non-homologous end joining pathways of DNA double-strand break repair have overlapping roles in the maintenance of chromosomal integrity in vertebrate cells. EMBO J. 17: 5497-5508.

Takisawa, H., Mimura, S., and Kubota, Y. 2000. Eukaryotic DNA replication: From pre-replication complex to initiation complex. Curr. Opin. Cell Biol. 12: 690-696.

Thelen, M.P., Venclovas, C., and Fidelis, K. 1999. A sliding clamp model for the Rad1 family of cell cycle checkpoint proteins. Cell 96: 769-770.

Tibbetts, R.S. and Abraham, R.T. 2000. PI3K-related kinases: Roles in cell-cycle regulation and DNA damage responses. In Signaling networks and cell cycle control: The molecular basis of cancer and other diseases (ed. J.S. Gutkind), pp. 267-301. Humana Press, Totowa, NJ.

Tibbetts, R.S., Brumbaugh, K.M., Williams, J.M., Sarkaria, J.N., Cliby, W.A., Shieh, S.Y., Taya, Y., Prives, C., and Abraham, R.T. 1999. A role for ATR in the DNA damage-induced phosphorylation of p53. Genes \& Dev. 13: 152-157.

Tibbetts, R.S., Cortez, D., Brumbaugh, K.M., Scully, R., Livingston, D., Elledge, S.J., and Abraham, R.T. 2000. Functional interactions between BRCA1 and the checkpoint kinase ATR during genotoxic stress. Genes \& Dev. 14: 2989-3002.

Venclovas, C. and Thelen, M.P. 2000. Structure-based predictions of Rad1, Rad9, Hus 1 and Rad17 participation in sliding clamp and clamp-loading complexes. Nucleic Acids Res. 28: 2481-2493.

Wakayama, T., Kondo, T., Ando, S., Matsumoto, K., and Sugimoto, K. 2001. Pie1, a protein interacting with Mec1, controls cell growth and checkpoint responses in Saccharomyces cerevisiae. Mol. Cell. Biol. 21: 755-764.

Wang, Y., Cortez, D., Yazdi, P., Neff, N., Elledge, S.J., and Qin, J. 2000. BASC, a super complex of BRCA1-associated proteins involved in the recognition and repair of aberrant DNA structures. Genes \& Dev. 14: 927-939.

Weinert, T. 1997. Yeast checkpoint controls and relevance to cancer. Cancer Surv. 29: 109-132.

Wright, J.A., Keegan, K.S., Herendeen, D.R., Bentley, N.J., Carr, A.M., Hoekstra, M.F., and Concannon, P. 1998. Protein kinase mutants of human ATR increase sensitivity to UV and ionizing radiation and abrogate cell cycle checkpoint con- 
trol. Proc. Natl. Acad. Sci. 95: 7445-7450.

Wu, X., Ranganathan, V., Weisman, D.S., Heine, W.F., Ciccone, D.N., O'Neill, T.B., Crick, K.E., Pierce, K.A., Lane, W.S., Rathbun, G., et al. 2000. ATM phosphorylation of Nijmegen breakage syndrome protein is required in a DNA damage response. Nature 405: 477-482.

Xu, B., Kim, S.T., and Kastan, M.B. 2001. Involvement of Brca1 in S-phase and G(2)-phase checkpoints after ionizing irradiation. Mol. Cell. Biol. 21: 3445-3450.

$\mathrm{Xu}, \mathrm{Y}$. and Baltimore, D. 1996. Dual roles of ATM in the cellular response to radiation and cell growth control. Genes \& Dev. 10: $2401-2410$.

Yang, D.Q. and Kastan, M.B. 2000. Participation of ATM in insulin signalling through phosphorylation of eIf-4E-binding protein 1. Nat. Cell Biol. 2: 893-898.

Yao, S.L., Akhtar, A.J., McKenna, K.A., Bedi, G.C., Sidransky, D., Mabry, M., Ravi, R., Collector, M.I., Jones, R.J., Sharkis, S.J., et al. 1996. Selective radiosensitization of p53-deficient cells by caffeine-mediated activation of $\mathrm{p} 34 \mathrm{cdc} 2$ kinase. Nat. Med. 2: 1140-1143.

Yavuzer, U., Smith, G.C., Bliss, T., Werner, D., and Jackson, S.P. 1998. DNA end-independent activation of DNA-PK mediated via association with the DNA-binding protein C1D. Genes \& Dev. 12: 2188-2199.

Yu, J., Zhang, L., Hwang, P.M., Rago, C., Kinzler, K.W., and Vogelstein, B. 1999. Identification and classification of p53regulated genes. Proc. Nat1. Acad. Sci.96: 14517-14522.

Zakian, V.A. 1995. ATM-related genes: What do they tell us about functions of the human gene? Cell 82: 685-687.

Zhao, S., Weng, Y.C., Yuan, S.S., Lin, Y.T., Hsu, H.C., Lin, S.C., Gerbino, E., Song, M.H., Zdzienicka, M.Z., Gatti, R.A., et al. 2000. Functional link between ataxia-telangiectasia and Nijmegen breakage syndrome gene products. Nature 405: 473 477.

Zhou, B.B.S. and Elledge, S.J. 2000. The DNA damage response: Putting checkpoints in perspective. Nature 408: 433-439.

Ziv, Y., Banin, S., Lim, D.S., Canman, C.E., Kastan, M.B., and Shiloh, Y. 2000. Expression and assay of recombinant ATM. Methods Mol. Biol. 99: 99-108. 


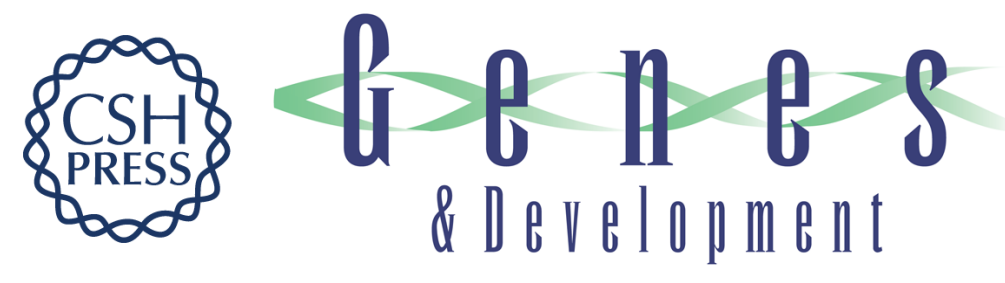

\section{Cell cycle checkpoint signaling through the ATM and ATR kinases}

Robert T. Abraham

Genes Dev. 2001, 15:

Access the most recent version at doi:10.1101/gad.914401

References This article cites 145 articles, 77 of which can be accessed free at: http://genesdev.cshlp.org/content/15/17/2177.full.html\#ref-list-1

License

Email Alerting Receive free email alerts when new articles cite this article - sign up in the box at the top Service right corner of the article or click here.

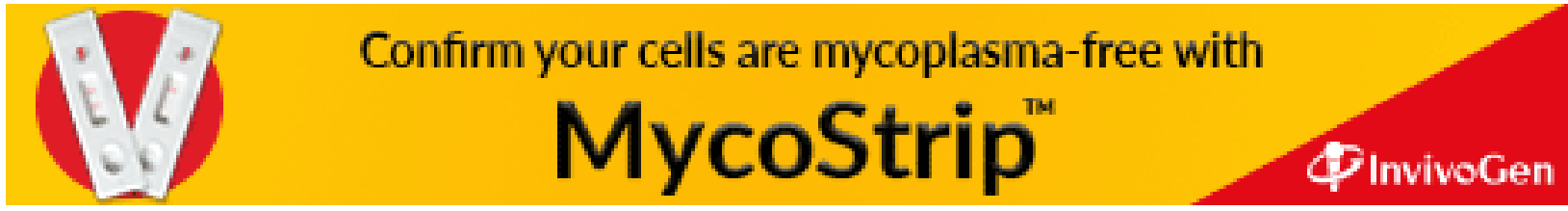

